Araştırma Makalesi / Research Article

\title{
AHP Yöntemi'nin Heyelan Duyarlılık Haritalarının Üretilmesinde Kullanımı ve Uygulaması (Sinop ve Yakın Çevresi)
}

Utilization and Application of AHP Method in Landslide Susceptibility Mapping Production (Sinop and its Surroundings)

\section{Seda ÇELLEK ${ }^{1}$, Fikri BULUT ${ }^{2}$, Hakan ERSOY ${ }^{2}$}

${ }^{1}$ Ahi Evran Üniversitesi, Mühendislik-Mimarlık Fakültesi, Jeoloji Mühendisliği Bölümü, KIRŞEHİR

${ }^{2}$ Karadeniz Teknik Üniversitesi, Mühendislik Fakültesi, Jeoloji Mühendisliği Bölümü, TRABZON

$\begin{array}{lll}\text { Geliş (received) } & : & \text { 05 Haziran (June) } 2015 \\ \text { Düzeltme (revised) } & : & \text { 13 Ağustos (August) } 2015 \\ \text { Kabul (accepted) } & : & \text { 20 Ağustos (August) } 2015\end{array}$

ÖZ

Bilgisayar destekli haritalama teknolojileri ve bunların geliştirilmesinde kullanılan yöntemlerde meydana gelen gelişmeler, daha yüksek performansa sahip heyelan duyarlılık haritalarının üretilmesini sağlamıştır. Bu çalışmada, bu yöntemlerden biri olan AHP'nin (Analitik Hiyerarşi Süreci) heyelan duyarlılık haritalarının üretilmesinde kullanımına ilişkin ayrıntılı bir literatür derlemesi yapılmış, ayrıca AHP ile Sinop ve çevresinin heyelan duyarlılık değerlendirilmesi gerçekleştirilmiştir. Heyelan duyarlılığının değerlendirilmesinde bakı, litoloji, arazi kullanım sınıfı, yamaç eğriselliği, eğim, yükseklik, anayola, akarsuya ve yapısal unsurlara yakınlık, çalışma sahasında heyelanları kontrol eden faktörler olarak dikkate alınmıştır. Kullanılan faktörler ağırlık değerlerine göre grid haritalarına dönüştürülmüş ve karşılaştırma matrisindeki değerlerin değişik şekillerde ele alınması ile çeşitli heyelan duyarlılık haritaları üretilmiştir. Analiz sonuçları, heyelanları temelde kontrol eden faktörlerin anayola uzaklık, bakı ve litoloji olduğunu göstermiştir. Sonuç olarak, heyelan duyarlılığı açısından Sinop ve yakın çevresindeki çalışma sahasının, \% 10.77'sinin çok düşük derecede heyelana duyarlı, \% 10.59'unun düşük derecede heyelana duyarl1, \% 52.64'ünün orta derecede heyelana duyarlı, \%25.66'sının yüksek derecede, \% 0.34'ünün çok yüksek derecede heyelana duyarlı olduğu belirlenmiştir. Bu çalışma sonucunda, özellikle son yıllarda artan biçimde kullanılan AHP'nin çalışma alanı için yüksek performans sağladığı saptanmıştır.

Anahtar Kelimeler: Analitik hiyerarşi süreci (AHP), Gerze, Heyelan, Heyelan Duyarlılı̆̆ 1 , Sinop.

S. Çellek

E-posta:sedacellek@ahievran.edu.tr 
Çellek, Bulut, Ersoy

\section{ABSTRACT}

Computer-aided mapping technologies and developments used in improvement of these methods have led to the production of higher performing landslide susceptibility maps. In this study, a thorough review of the literature about the production of landslide susceptibility maps by using AHP (Analytic Hierarchy Process) was made and, also, landslide susceptibility evaluation of Sinop and its surroundings was analyzed by AHP. In the evaluation of landslide susceptibility factors such as aspect, lithology, land use, curvature, slope, elevation and proximity to the main road, river and structural elements are considered to be controlling factors in the landslide process. These factors are turned into grid maps according to their weighted values and by handling the values in comparison matrices in different manners, and variety of landslide susceptibility maps produced. Analysis of results showed that main controlling factors of landslides are the proximity to main road, aspect and lithology. As a result, in terms of landslide susceptibility, very low landslide susceptibility is determined in the 10.77\%, low landslide susceptibility determined in the 10.59\%, moderate landslide susceptibility is determined in the $52.64 \%$, high landslide susceptibility determined in the $25.66 \%$, very high landslide susceptibility determined in the $0.34 \%$, of Sinop and its proximity area. This study reveal that AHP, which has been used increasingly in the last years, provides high performance in the study area.

Key Words: Analytical Hierarchy Process (AHP), Gerze, Landslide, Landslide Susceptibility, Sinop.

\section{GíRiș}

Sanayileşme ve nüfus artışına bağlı olarak yeni yerleşim alanlarına olan gereksinim her geçen gün daha da artmaktadır. Buna bağlı olarak, yeni karayolu, demiryolu, liman, havaalanı gibi ana ulaşım bileşenleri inşa edilmekte ve bunlar için de yer ihtiyacı artmaktadır. Çoğu zaman yer seçimi için, her ölçütü karşılayan uygun alanlar ve/veya güzergahlar bulmak, neredeyse olanaksız hale gelmektedir. Ancak, bir sahada var olan doğal tehlikenin önceden bilinmesi, daha ekonomik ve emniyetli çözümlerin geliştirilmesini sağlayabilmektedir. En yaygın doğal tehlikelerden biri heyelanlar olup, dünyanın hemen her coğrafyasında, bu afetlere ve sonuçlarına sıklıkla rastlanmaktadır.
Heyelanlardan kaynaklanan zararların azaltılmasında ilk aşamada kullanılan en etkin yöntemlerin başında, uygun yer seçimi gelmektedir. Uygun yer seçimi için heyelanların ve gelecekte olması muhtemel heyelanların alansal yayılımının doğru biçimde bilinmesi hayati öneme sahiptir. Mevcut heyelanlar çeşitli yöntemlerle üretilen heyelan envanter çalışmaları ile ortaya konulabilirken, gelecekte olması muhtemel heyelanların alansal yayılımları heyelan duyarlılık değerlendirmeleri ile tespit edilebilmektedir.

Teknolojik gelişmeler heyelan duyarlılığını daha kolay uygulanabilir ve daha yüksek hassasiyette haritalar üretilebilir hale gelmiştir. Heyelan duyarlılığının değerlendirilmesinde 
ağırlıklı olarak istatistiksel ve esnek hesaplama yöntemleri ile uzman görüşüne dayalı yöntemlerin kullanımı yaygınlaşmıştır. $\mathrm{Bu}$ yöntemlerden biri olan AHP (Analitik Hiyerarşi Süreci), özellikle son on yılda heyelan duyarlılığının değerlendirilmesinde yaygın bir kullanım alanı bulmuştur. $\mathrm{Bu}$ nedenle bu çalışmada AHP'nin heyelan duyarlılığının değerlendirilmesinde kullanımına ilişkin literatür incelenmiş ve elde edilen sonuçlar yorumlanmıştır. Bunun yanı sıra, yöntem, heyelanların gözlendiği Sinop ve yakın çevresinde uygulanmış ve heyelan duyarlılık haritaları üretilmiştir. Diğer bir ifade ile AHP'nin heyelan duyarlılığında kullanımının irdelenmesi ve uygulanması çalışmanın amacını oluşturmaktadır.

$\mathrm{Bu}$ amaçla son onbeş y1la ait (2000-2015) literatür ayrıntılı incelenmiş, konusu heyelan duyarlılı̆̆ ve AHP olan çalışmalar derlenerek (Çizelge 1) genel bir yorumlama yapılmıştır.

Çizelge 1. Son on beş yıla ait AHP ile hazırlanan heyelan duyarlılığına ait çalışmalar.

Table 1. Landslide susceptibility studies in the Last Fifteen Years Prepared with AHP.

\begin{tabular}{|l|l|l|l|}
\hline \multicolumn{1}{|c|}{ KAYNAK } & ÜLKE & \multicolumn{1}{c|}{ KAYNAK } & ÜLKE \\
\hline Yang vd. (2015) & Çin & Quan and Lee (2012) & Kore \\
\hline Shafri vd. (2010) & Malezya & Akgun (2012) & Türkiye \\
\hline Zare vd. (2014) & İran & Pourghasemi vd. (2012a) & İran \\
\hline Kornejady vd. (2014) & İran & Pourghasemi (2012b) & İran \\
\hline Saadatkhah vd. (2014a) & Malezya & Hasekioğulları ve Ercanoğlu (2012) & Türkiye \\
\hline Althuwaynee vd. (2014) & Kore & Mondal ve Maiti (2012) & Hindistan \\
\hline Habibi (2014) & İran & Thanh ve Smedt (2012) & Viyetnam \\
\hline Othman vd. (2014) & Malezya & Reis vd. (2012) & Türkiye \\
\hline Ivanova (2014) & Bulgaristan & Yanrong vd. (2012) & Çin \\
\hline Kavzoglu vd. (2014) & Türkiye & Diop (2012) & G. Afrika \\
\hline Daneshvar (2014) & İran & Yalcin vd. (2011) & Türkiye \\
\hline Ahmed (2014) & Bangadeş & Khezri (2011) & İran \\
\hline Saadatkhah vd. (2014b) & Malezya & Guoqing vd. (2011) & Çin \\
\hline Niu vd. (2014) & Çin & Rozos vd. (2011) & Yunanistan \\
\hline Chalkias vd. (2014) & Yunanistan & Daneshvar ve Bagherzadeh (2011) & İran \\
\hline Feizizadeh ve Blaschke (2013a) & İran & Suh vd. (2011) & Kore \\
\hline Feizizadeh vd. (2014a) & İran & Gaprindashvili (2011) & Gürcistan \\
\hline Qiu vd. (2014) & Çin & Youssef vd. (2011) & Misır \\
\hline Pourghasemi vd. (2014) & İran & Ghosh vd. (2011) & Hindistan \\
\hline Chen vd. (2014) & Çin & Akgün ve Türk (2010) & Türkiye \\
\hline Youssef (2015) & S. Arabistan & Feizizadeh vd. (2010) & İran \\
\hline Margarint ve Niculita (2014) & Romanya & Intarawichian ve Dasananda (2010) & Tayland \\
\hline Ilanloo vd. (2014) & İran & Gorsevski ve Jankowski (2010) & Moskova \\
\hline Tazik vd. (2014) & İran & Barredo vd. (2000) & İspanya \\
\hline
\end{tabular}


Çellek, Bulut, Ersoy

Çizelge 1. (devamı)

Table 1. (cont'd.)

\begin{tabular}{|l|l|l|l|}
\hline Moradi ve Rezaei (2014) & İran & Marjanoviç (2009a) & Sırbistan \\
\hline Althuwaynee ve Pradhan (2014) & Malezya & Vahidnia vd. (2009) & İran \\
\hline Feizizadeh (2014b) & İran & Prabu ve Ramakrishnan (2009) & Hindistan \\
\hline Kayastha vd. (2013) & Nepal & Marjanoviç (2009b) & Sırbistan \\
\hline Marjanović vd. (2013) & Sirbistan & Jin vd. (2009) & Kore \\
\hline Calligaris vd. (2013) & Pakistan & Chuan vd. (2009) & Çin \\
\hline Feızızadeh vd. (2013a) & İran & Wu ve Chen (2009) & Tayvan \\
\hline Ma vd. (2013) & Çin & Marjanoviç vd. (2009) & Surbistan \\
\hline Bathrellos vd. (2013) & Yunanistan & Yalçın (2008) & Türkiye \\
\hline Feizizadeh ve Blaschke (2013b) & İran & Akgün vd. (2008) & Türkiye \\
\hline Mustafa vd. (2013) & Malezya & Domakinis vd. (2008) & Yunanistan \\
\hline Bhatt vd. (2013) & Nepal & Ercanoğlu vd. (2008) & Türkiye \\
\hline Demir vd. (2013) & Türkiye & Kamp vd. (2008) & Pakistan \\
\hline Pourghasemi vd. (2013) & İran & Abella ve Van Westen (2007) & Küba \\
\hline Bagherzadeh ve Daneshvar (2013) & İran & Akgün ve Bulut (2007) & Türkiye \\
\hline Park vd. (2013) & Kore & Yalçın ve Bulut (2007) & Türkiye \\
\hline Mondal ve Maiti (2013) & Hindistan & Ladas vd. (2007) & Yunanistan \\
\hline Feizizadeh vd. (2013) & İran & Gorsevski vd. (2006) & Moskova \\
\hline Solle vd (2013) & Endonezya & Yoshimatsu ve Abe (2006) & Japonya \\
\hline Feizizadeh vd. (2013b) & İran & Ayalew vd. (2005) & Japonya \\
\hline Chingkhei vd. (2013) & Hindistan & Marko Komac (2005) & Slovenya \\
\hline Solle (2013) & Endonezya & Esmali ve Ahmadi (2003) & İran \\
\hline Yamani vd. (2013) & İran & Ownegh (2004) & İran \\
\hline Mezughi vd. (2012) & Malezya & Komac (2003) & Slovenya \\
\hline Teimouri ve Graee (2012) & İran & Ouri ve Amirian (2009) & İran \\
\hline Moradi vd. (2012) & İran & Barredo vd. (2000) & İspanya \\
\hline & & & \\
\hline
\end{tabular}

Daha önce de söz edildiği gibi, heyelan duyarlı1ık haritası üretmede, olasılık yöntemi (frekans oranı), analitik hiyerarşi süreci (AHP), iki değişkenli, çok değişkenli, lojistik regresyon, bulanık mantık ve yapay sinir ağları gibi değişik yöntemler kullanılmaktadır. Ancak, bu çalışmaların birbirlerinden ayrıldıkları noktalar olsa da en önemli ortak noktaları, son yıllarda birçok alanda kullanılan coğrafi bilgi sistemlerini (CBS) kullanmalarıdır. CBS, verilerin bir arada, hızlı, ekonomik ve etkin bir şekilde değerlendirilmesini sağlamaktadır. Nicel yöntemlere uygulanabilirliği birçok çalışmayla da ortaya konmuş CBS ve mevcut istatistiksel programların entegrasyonunun sağlanması ile duyarlılık için kullanılacak parametrelerin üretimi de, daha kolay bir hal almıştır. Ancak, kullanılan yöntemin uygunluğunun yanı sıra, heyelan duyarlılık çalışmalarında kullanılan verinin kalitesi de oldukça önemlidir. 


\section{Parametre Seçimi}

Hazırlanan heyelan duyarlılık haritası için parametre seçiminde belirsizliklerin giderilmesi için literatür değerlendirmesi yapılarak çözüm bulunmaya çalışılmıştır. Çalışma alanı seçminden sonra en önemli kriter parametre ve yöntem seçimidir. Son 30 yılda yapılan yaklaşık 300 çalışma değerlendirilerek, çalışma sahası için uygun olan parametreler belirlenmeye çalışılmıştır. Çalışma sahası için en uygun parametrelerden olan yağış, çalışma alanında sadece bir adet yağış istasyonu olmasından dolayı değerlendirmeye alınamamıştır. Jeoteknik ve yeraltisuyu durumunu temsil edecek parametre haritaları ise alanın büyük olması, zamanın kısıtlı olması ve maddi olanakların yetersizliğinden dolayı kullanılamamıştır. Envanter haritasının hazırlanmasında alanda çok fazla sayıda heyelan olması nedeni ile heyelanların türleri ve derinlikleri belirlenememiştir.

Hazırlayıcı faktörlerden jeoloji için yapılan değerlendirmeye göre \% 43 ile litoloji en çok tercih edilen parametre olurken bunu \% 24 ile zemin özelliği/ayrışma ve \% 22 ile yapısal özellikler takip etmektedir. \% 11'lik kısımdaki jeoteknik parametreler ve yeraltısuyu durumu ise kesin sonuçlar vermesine rağmen zaman ve maliyet açısından tercih edilmemektedir.

Hazırlayıcılardan, topoğrafik faktörler için yapılan değerlendirmede en çok kullanılan parametrenin yamaç eğimi olduğu, bunu yamaç yönelimi, yükseklik ve akarsu faktörlerinin izlediği belirlenmiştir. En çok kullanılan parametrelerin yüzde dağılımı ise yamaç eğimi $\%$ 27, yamaç yönelimi \% 17, yükseklik \% 16, yamaç eğriselliği ve akarsuya yakınlık \% 28 şeklindedir. Geriye kalan \% 12'lik kısmı ise Jeomorfolojik Birimler/Özellikler, Topoğrafik
Nemlilik Endeksi (TWI), Akarsu Aşındırma Gücü Endeksi (SPI), Sediman Taşıma Kapasite Endeksi (LSI) parametreleri oluşturmaktadır.

Hazırlayıc1 faktörlerden sonuncusu çevresel etkiler ise arazi kullanımı/bitki örtüsü \% 79, yollar \% 16 ve diğer faktörler \% 5 olmak üzere değerlendirilmiştir.

Tetikleyiciler ise kendi arasında üç sınıfa ayrilmaktadır. Bunlar, literatürde tercih edilmeyen ya da veri sıkıntısı yaşanan faktörlerdir. Bu faktörler içerisinde yağış, \% 75 ile en çok tercih edilen parametredir. Yağışı, \% 21 ile sismik aktivite ve $\% 4$ ile antropojenik etki izelemektedir.

Çalışmalardan elde edilen veriler değerlendirildiğinde, yamaç eğimi, arazi kullanımı/bitki örtüsü ve litoloji parametrelerinin en çok kullanılan parametreler olduğu belirlenmiştir. Belirlenen 21 parametreden ilk 9 tanesi, diğerlerine oranla daha çok tercih edilmiştir (Çizelge 2). Literatürde en çok kullanılan 10 parametre belirlenmiştir. "Zemin özelliği/ayrışma" parametresi dışında kalan diğer 9 parametre çalışmada kullanılmıştır. 8 . sıradaki "Zemin özelliği/Ayrışma” parametresi, alanda sadece tortul birimler değerlendirildiği için tercih edilmemiştir. Arazi sınıflaması, uydu görüntülerinden kontrollü sinıflama yapılarak üretilmiştir. Çalışma alanı, sahil yolu projesinin son kısmını oluşturması ve son üç yıldır yapımının devam etmesi nedeni ile tercih edilmiştir. Sayısal yükseklik modeli kullanılarak, alanın, eğim, bakı ve yükseklik paramatre haritaları elde edilmiştir. Son olarak jeoloji haritası kullanılarak, litoloji, akarsu ve tektonizma parametre haritaları üretilmiştir. 
Çellek, Bulut, Ersoy

Çizelge 2. Literatürde en çok kullanılan parametreler.

Table 2. The Parameters commonly used in the literature.

\begin{tabular}{|c|c|c|c|}
\hline En Çok Kullanılan Parametreler & Faktör & Parametre & $\begin{array}{c}\text { Atıf } \\
\text { Sayısı }\end{array}$ \\
\hline 1 & $\mathrm{~T}$ & Yamaç Eğimi & 281 \\
\hline 2 & Ç & Arazi Kullanımı/Bitki Örtüsü & 239 \\
\hline 3 & $\mathrm{~J}$ & Litoloji & 236 \\
\hline 4 & $\mathrm{~T}$ & Bak1/Yamaç Yönü & 175 \\
\hline 5 & $\mathrm{~T}$ & Yükseklik & 169 \\
\hline 6 & $\mathrm{~T}$ & Akarsu A $\breve{g} 1 /$ Drenaj A $\breve{g}_{1}$ & 153 \\
\hline 7 & $\mathrm{~T}$ & Yamaç Eğriselliği & 147 \\
\hline 8 & $\mathrm{~J}$ & Zemin Özelliği/Ayrışma & 136 \\
\hline 9 & $\mathrm{~J}$ & Yapısal Unsurlara Uzaklık & 120 \\
\hline 10 & Ç & Yollar & 48 \\
\hline 11 & $\mathrm{~T}$ & Topoğrafik Nemlilik Endeksi (TWI) & 46 \\
\hline 12 & $\mathrm{~J}$ & Yeraltısuyu (Su Durumu) & 38 \\
\hline 13 & $\operatorname{Tr}$ & Yağış & 36 \\
\hline 14 & $\mathrm{~T}$ & Akarsu Aşındırma Gücü Endeksi (SPI) & 34 \\
\hline 15 & $\mathrm{~T}$ & Jeomorfolojik Birimler/Özellikler & 30 \\
\hline 16 & $\mathrm{~J}$ & Jeoteknik Özellikler & 21 \\
\hline 17 & $\mathrm{C}$ & Diğer & 17 \\
\hline 18 & $\mathrm{~T}$ & Sediman Taşıma Kapasitesi Endeksi (LSI) & 15 \\
\hline 19 & $\mathrm{~T}$ & Diğer & 12 \\
\hline 20 & $\operatorname{Tr}$ & Sismik Aktivite & 10 \\
\hline 21 & $\operatorname{Tr}$ & Antropojenik Aktivite & 2 \\
\hline
\end{tabular}

T: Topoğrafik Faktörler, Ç: Çevresel Etkiler, J: Jeolojik Faktörler, Tr: Tetikleyici Faktörler

\section{Analitik Hiyerarşi Süreci (AHP)}

Özellikle 1990'lı yılların başından itibaren coğrafi bilgi sistemlerindeki ve bilgisayar teknolojisindeki gelişmelere paralel olarak, geniş bir kullanım alanına sahip olan heyelan değerlendirmelerinde, farklı yöntemler kullanılmaktadır. Analitik Hiyerarşi Süreci
(AHP) ile karmaşık ve düzensiz problemler alt gruplara ayrılarak hiyerarşik bir yapı oluşturulur.

AHP, kişisel kararlardan karmaşık işletme kararlarına kadar geniş bir alanda kullanılabilen bir araçtır. Teorinin başarısı, basitliğinden ve değişik koşulların her birinde aynı şekilde kullanılabilme özelliğinden kaynaklanmaktadır. 
Hiyerarşinin ilk düzeyi, genel amacın, heyelan duyarlılık haritası üretmek olduğunu göstermektedir. İkinci düzeydeki kriterler (eğim, bakı, yükseklik, arazi sınıfı, jeoloji, faya, akarsuya ve yola yakınlık) genel amaca ulaşmaya katkıda bulunacaktır. Üçüncü düzeydeki her bir karar alternatifi (sınıflandırılmış alt kriterler) ise her bir kritere göre değerlendirilir (Yalçın, 2005).

Heyelan duyarlılık çalışmalarında dikkate alınan AHP yöntemi, heyelan oluşumunda etkin olduğu düşünülen parametrelerin birbirlerine göre etkinlik derecelerinin belirlenmesi ve duyarlılık haritası oluşturulurken dikkate alınması gereken parametrelerin seçilmesi amacıyla uygulanır. Heyelan duyarlılık analizlerinde herhangi bir parametrenin etkisi, sabit kabul edilebilmektedir. $\mathrm{Bu}$ amaçla, eğer bir piksel heyelanlı ise (piksel değeri = 1), söz konusu piksele karşılık gelen parametre değerleri, veri tabanını oluşturacak şekilde, farklı dosyalar halinde saklanır. Eğer, söz konusu pikselde heyelan yoksa (piksel değeri $=0$ ), parametrik veri dosyalarında herhangi bir işlem yapılmadan, bir sonraki veri grubuna geçilmektedir. Bu şekilde, dikkate alınan her bir parametre ve alt grupları için, heyelanlı piksel sayıları ve çalışma alanındaki sayıları, otomatik olarak belirlenir. Gerek yerleşilebilirlik analizinde kullanılan puanları, gerekse Analitik Hiyerarşi Süreci'nde faktör ağırlıklarını belirlemede literatür çalışması ve uzmanlarla gerçekleştirilen görüşmelerden faydalanılır. Belirlenen puanlar, CBS ortamında hazırlanan haritalara öznitelik bilgisi olarak girilir. Daha sonra tüm haritalar raster formatına çevrilir ve faktörlerin belirlenen ağırlık katsayıları ile çarpılarak her hücre birimi başına hesaplanan değerler harita olarak elde edilir (Çellek, 2013).
Yapılan bu çalışmada, altlık haritalar hazırlanmıştır. Analitik Hiyerarşi yöntemiyle ağırlıklandırılan bu haritalar çakıştırılarak heyelana duyarlı alanlar belirlenmiştir.

Literatürde 2000-2015 yılları arasında yapılan çalışmalardan analitik hiyerarşi süreci ile heyelan duyarlil1k, risk ve tehlike haritası oluşturulan çalışmalar incelenmiştir. $\mathrm{Bu}$ çalışmalardan seçilen 100 tanesi ile istatistiksel bir değerlendirme yapılmıştır (Şekil 1).

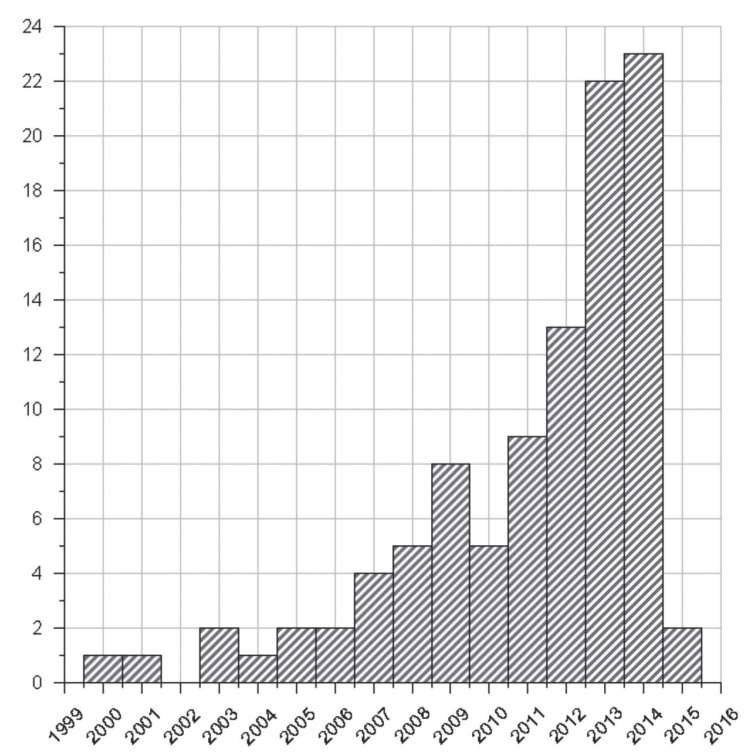

Şekil 1. AHP ile hazırlanan 100 çalışmanın yıllara göre dağılımı.

Figure 1. Yearly distribution of 100 studies prepared with AHP method.

AHP ile yapilan heyelan duyarlilik çalışmalarının ülkelere göre dağılımına bakıldığında (Şekil 2), ilk sırayı \% 28 ile İran'ın, ardından \% 12'i ile Türkiye'nin aldığı görülmektedir. Bunları, \% 8 ile Çin, \%7 ile Malezya, \% 5 ile Hindistan, Yunanistan, Kore ve 
$\% 4$ ile Endonezya ve Sirbistan takip etmektedir. \% 22'lik kısmı oluşturan diğer ülkeler ise; Bulgaristan, Bangladeş, Suudi Arabistan, Romanya, Vietnam, Gürcistan, Tayland, Tayvan, Küba, Misır, Afrika, Kanada, Moskova, Japonya, Slovenya, İspanya ve Pakistan'dır (Şekil 2).
Çalışmalarda 65 farklı parametre kullanılmıştır. 100 çalışmanın, 93'ünde yamaç eğimi, 81'inde litoloji (jeoloji-ayrışmapetrografi), 72'sinde bakı, 70'inde arazi kullanımı (arazi örtüsü), 68'inde drenaja uzaklık,), 57'sinde yükseklik, 52'sinde yola uzaklık, 42'sinde faya

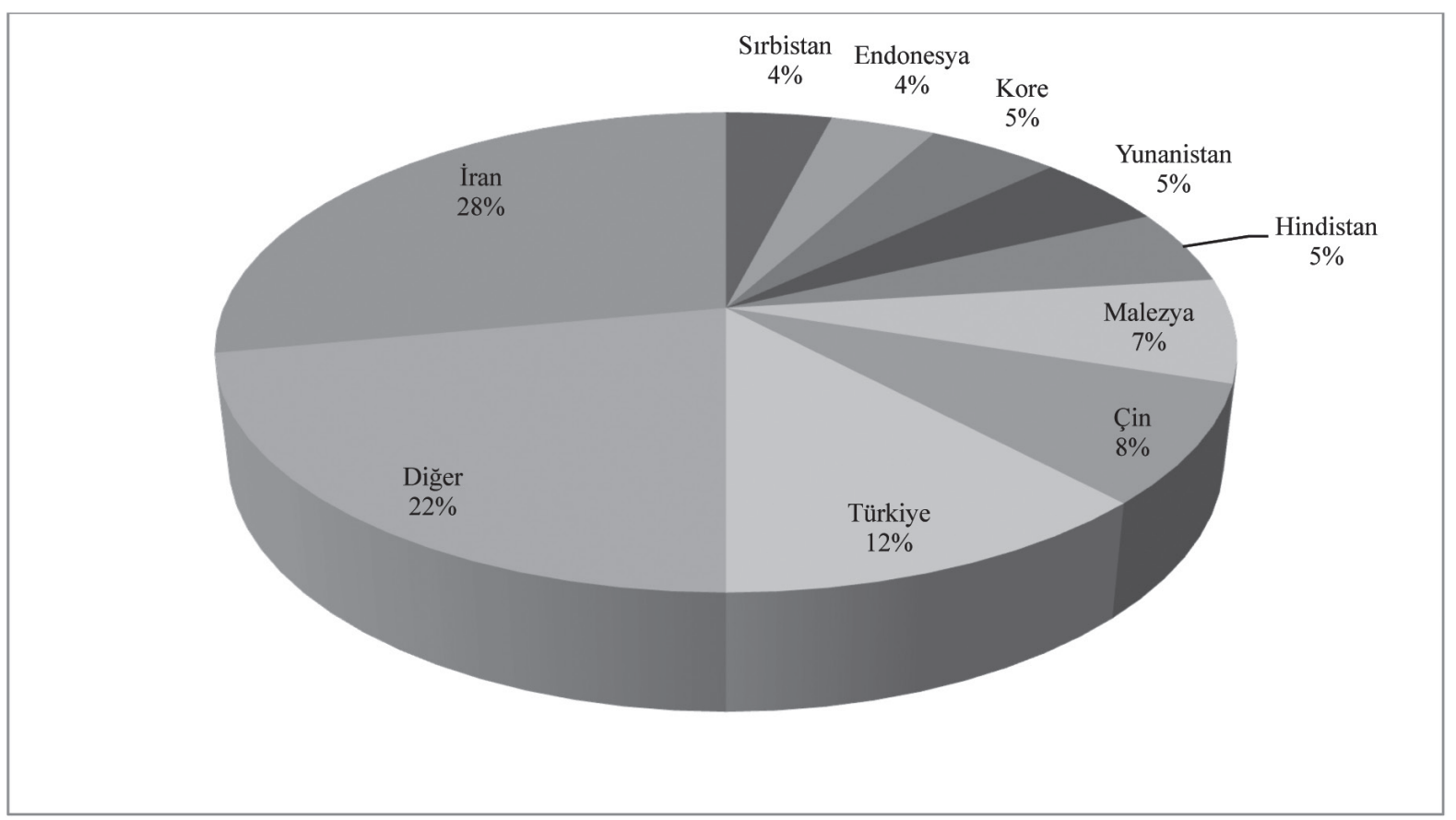

Şekil 2. AHP ile yapılan çalışmaların ülkelere göre dağılımı.

Figure 2. Distribution of AHP-related studies for different countries.

Çalışmaların \%43'ünde AHP tek yöntem olarak kullanılırken, \%15'inde AHP ve frekans oran1, \%12'sinde AHP ve lojistik regresyon yöntemi birlikte kullanılmıştır. AHP ile birlikte ikiden fazla yöntem ile heyelan duyarlılık haritası üretilen çalışmalarda, her yöntemin sonucu diğerleri ile kıyaslanmıştır. uzaklık, 42'sinde yağış, 30'unda eğrisellik, 15'inde NDVI (bitki örtüsü indeksi), 15'inde drenaj yoğunluğu, 15'inde zemin dokusu, 14'ünde TWI, 13'ünde SPI, 9'unda TFD (sismik yoğunluk) ve 9'unda süreksizlik parametresi kullanılmıştır (Şekil 3). 
Araştırma Makalesi / Research Article

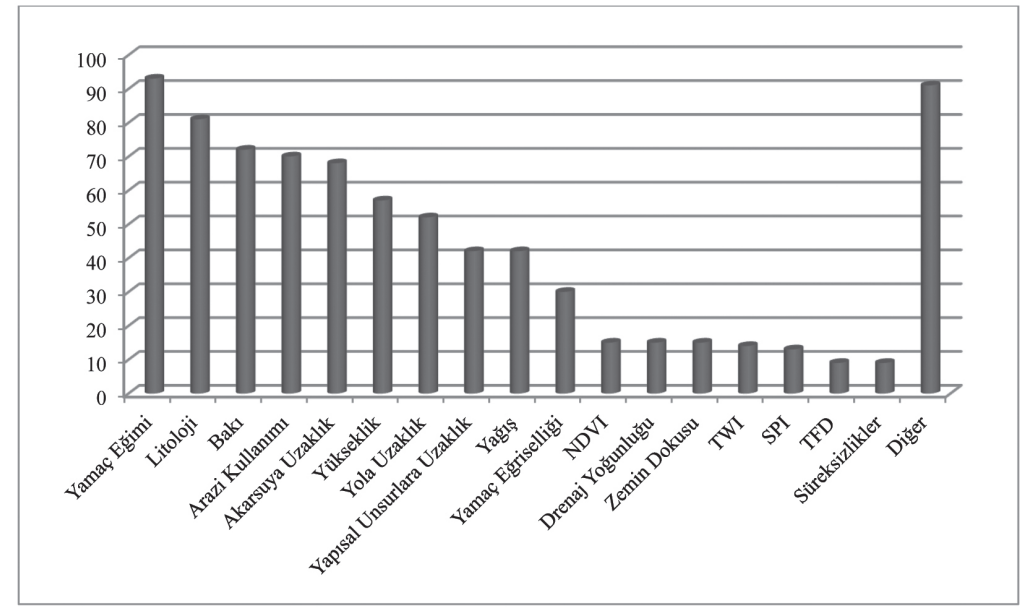

Şekil 3. Parametre sayılarının makalelere göre dağılımı.

Figure 3. The distribution of the number of parameters for articles.

\begin{tabular}{|c|c|c|}
\hline İnceleme Alanının Konumu & ve Genel & $12^{\prime}$ ve $42^{\circ} 06^{\prime}$ kuzey enlemleri ile $34^{0} 14^{\prime}$ ve $35^{\circ}$ \\
\hline Özellikleri & & 26' doğu boylamları arasında yer almaktadır. \\
\hline Karadeniz Bölgesi'nin Orta $\mathrm{I}$ & Karadeniz & Heyelan duyarlı1ık çalışması, Sinop-Gerze \\
\hline $\begin{array}{l}\text { ölümü'nde, Batı ve Doğu Karadeniz I } \\
\text { asında bir geçiş bölgesinde yer alan } s\end{array}$ & $\begin{array}{l}\text { z Bölümleri } \\
\text { Sinop, } 41^{0}\end{array}$ & $\begin{array}{l}\text { sahil kesimini kapsamaktadır (Şekil 4). Çalışma } \\
\text { alanının yüzölçümü } 300 \mathrm{~km}^{2} \text { 'dir. }\end{array}$ \\
\hline
\end{tabular}

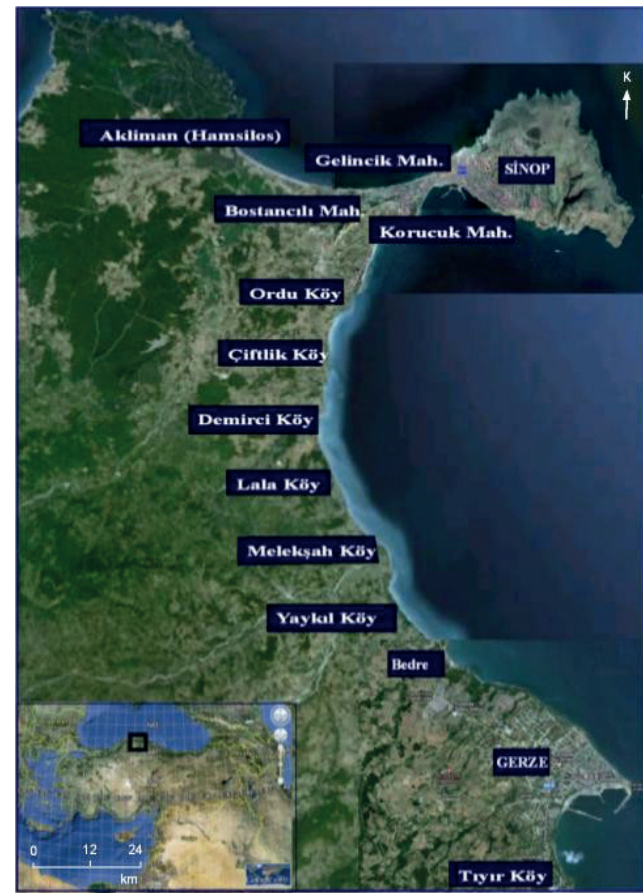

Şekil 4. Sinop ilinin yer bulduru haritası.

Figure 4. Location map of Sinop. 
Sinop, Anadolu'nun kuzeye doğru en çok ilerleyen ve İnceburun ile sonlanan kara çıkıntısına doğudan birleşen küçük bir yarımadanın yamacına kurulmuştur. Topraklarının \% 74'ü dağlardan, \% 23'ü platolardan, \% 2'si ovalardan oluşan il, kuzeyden güneye doğru gittikçe yükselen bir morfolojiye sahiptir. Yarımada sahilleri çoğunlukla dik falezeler şeklindedir (Aktimur vd., 1993).

Sinop, Doğu ve Batı Karadeniz iklim özelliklerinin iç içe geçtiği bir yerdir. İl merkezinde mevsimler arası sıcaklık farkları çok büyük olmamasına rağmen, kuzeyde yer alan kıyı kesimlerde Karadeniz iklimi, güneyde ise kıyı boyunca uzanan dağlar nedeniyle karasal iklim hakimdir. Y1l boyunca esen, sürekli rüzgârlar etkilidir. İlin konumu, kuzey (yıldız) rüzgârlarının zaman zaman çok şiddetli esmesine neden olur (Sinop ÇED, 2007). Kış aylarında ise, özellikle akşam saatlerinde kuzeybatı (karayel) ve güneybatı (lodos) rüzgarları etkili olmaktadır. Kıyılardan içeri doğru yağış karakteri değişmekte ve miktarı azalmaktadır. Karadeniz dağlarının iç kesimlerinde, dağların güney yamaçlarında, yazları sıcak ve kurak, kışları soğuk ve kar yağışlı olan karasal iklim görülür. Yazın belli bir dönem dişında, bütün yıl nemli ve yağışlı geçer. Y1llık yağışların, \% 30'u kış mevsiminde (Aralık, Ocak, Şubat), \%18'i ilkbahar mevsiminde (Mart, Nisan, May1s), \%16's1 yaz mevsiminde (Haziran, Temmuz, Ağustos) ve \%36's1 sonbahar mevsiminde (Eylül, Ekim, Kasım) meydana gelmektedir. Yörenin doğal bitki örtüsünü ormanlar oluşturmaktadır. Bitki örtüsü çok zengin ve yoğun olup yükselti kuşaklarına göre farklılaşmaktadır. İlin kıyı şeridinde Akdeniz bitkileri de görülür. Meşe, defne, karaağaç, çınar, fındık, kızılcık, kayın, gürgen, karaçam ve sarıçamdan oluşan bu bitki örtüsü, yükseltinin
1.800 metreye ulaştı̆̆ 1 kesime kadar yayılır (Aktimur vd., 1993; Sinop ÇED, 2007).

Üst Kretase'den günümüze çeşitli yaş ve türde litolojik birimler bulunur. Tektonik olarak, Ballıfakı fayı, Akveren, Atbaşı ve Kusuri formasyonları içinde gelişmiş ve bu formasyonları deforme etmiş ters bir faydır (Barka vd., 1983; Aktimur vd., 1993). Erikli fay1; Ayancık güneyinde, doğu-batı Gerze güneyinde, güneydoğu-kuzeybatı yönünde uzanan $200 \mathrm{~km}$ uzunluğunda ters bir faydır. Bu fay zonu genelde Akveren ve Atbaşı formasyonlarının dokanakları arasında izlenir ve Akveren formasyonunun çökeliminden hemen sonra oluşmuştur (Barka vd., 1983; Aktimur vd., 1993).

İnceleme alanında Üst Kretase-Kuvaterner zaman aralığında oluşmuş formasyonların yer aldığ1 görülür. Tabanda Hamsaros Formasyonu (aglomera, lav, tüf) bulunmaktadır. Daha üstte Paleosen yaşlı kireçtaşı, şeyl, marn ve çamurtaşından oluşan Akveren Formasyonu bulunur. Eosen yaşlı Atbaşı Formasyonu (kireçtaş1, kumtaş1, marn), Kusuri Formasyonu (kumtaş1, marn), sırasıyla gelmektedir. Daha sonra kumtaşı, kireçtaşı ve marndan oluşan Miyosen yaşlı Sinop Formasyonu gelir. Birimin üst kısımların yer alan Pliyo Kuvaterner yaşlı Sarıkum Formasyonu ise gevşek kumtaş1, çakı1 ve kumdan oluşur. Sarıkum Formasyonu üzerine sırasıyla gevşek kumtaşından oluşan BedireKayas1 Formasyonu ve alüvyonlar gelmektedir (Çellek, 2013).

\section{Materyal ve Metot}

Çalışma kapsamında inceleme alanı ile ilgili önceden hazırlanmış çalışmalar değerlendirilerek, ilgili kurumlardan gerekli veriler temin edilmiştir (Çizelge 3). 
Çizelge 3. Çalışmada kullanılan veri türleri ve kaynakları.

Table 3. The data types used in the study and their sources.

\begin{tabular}{|c|c|c|c|}
\hline Veri Türü & Ölçek & Veri Kaynağı & Üretilen Veri \\
\hline Topoğrafya Haritaları & $1 / 25.000$ & Harita Genel Komutanlığı & Akarsuya Yakınlık \\
\hline Sayısal Yükseklik Modeli & $1 / 25.000$ & MTA & $\begin{array}{c}\text { Eğim } \\
\text { Bakı } \\
\text { Eğrisellik }\end{array}$ \\
\hline Jeoloji Haritası & $1 / 25.000$ & MTA & $\begin{array}{c}\text { Litoloji } \\
\text { Yapıssal Unsurlara Uzaklık }\end{array}$ \\
\hline Heyelan Envanter & $1 / 500.000$ & MTA & Sinop ili envanteri \\
\hline $\begin{array}{c}\text { Sinop-Gerze meteroloji istasyonları } \\
53 \text { yıllık yağı̧̧ verisi }\end{array}$ & & $\begin{array}{c}\text { Meteroloji İşleri Genel } \\
\text { Müdürlüğü }\end{array}$ & Yağ1Ş \\
\hline $\begin{array}{c}\text { Quickbird Uydu Görüntüsü } \\
\text { Heyelan Verisi }\end{array}$ & $1 / 25.000$ & NİC firması & Arazi Sinıfı \\
\hline & AFAD & Envanter \\
\hline
\end{tabular}

Çalışma alanında yapılan haritalar ve raporlar 2009 y1lında Maden Tetkik Arama Genel Müdürlügü’nden (MTA) satın alınmıştır. 20092010 yılları arasında Sinop ili ve çevresinde meydana gelen heyelanlarla ilgili veriler Sinop Afet İşleri İl Müdürlüğü’nden (AFAD) temin edilmiş, 1980-2010 yılları arasında meydana gelen, sadece Sinop ili ve çevresi ile Gerze ilçesi ve çevresini içeren heyelan verileri incelenmiştir. Alınan heyelan verilerinin koordinatları belirlenmiş, 2010 yılında MTA'dan temin edilen ve 2007 yılına ait olan 1/25.000 ölçekli Sinop ili heyelan envanter haritasına işlenmiştir.
Çalışmada dikkate alınan AHP yöntemi, heyelan oluşumunda etkin olduğu düşünülen parametrelerin birbirlerine göre etkinlik derecelerinin belirlenmesi ve duyarlılık haritası oluşturulurken dikkate alınması gereken parametrelerin seçilmesi amaciyla uygulanmıştır. İlk olarak kriter ve karar alternatiflerine göre problemin grafiksel akış şeması oluşturulmuştur (Şekil 5). Hiyerarşinin ilk aşaması, heyelan duyarlıl1k haritası üretmektir. İkinci aşamadaki 9 adet kriter genel amaca ulaşmaya katkı sağlayacaktır. Son olarak, sınıflandırılmış alt kriterler her bir kritere göre değerlendirilecektir. 


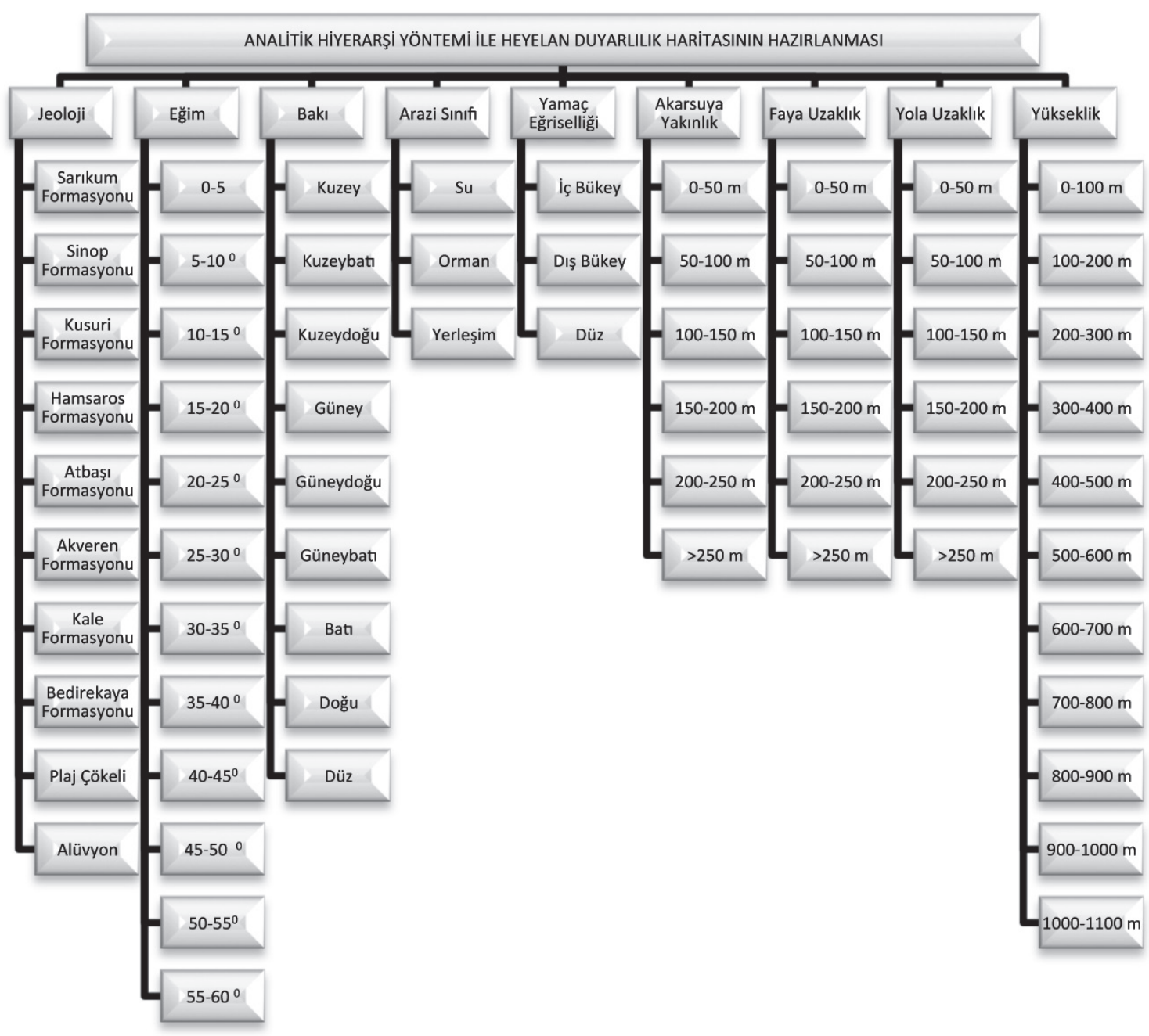

Şekil 5. Analitik Hiyerarşi Yöntemi (AHP) ile heyelan duyarlılık haritasının oluşturulması akış şeması.

Figure 5. Landslide susceptibility flow chart with AHP.

Kurumlardan temin edilen veriler ve arazi çalışmalarından elde edilen sonuçlar birleştirilerek Şekil 6'daki envanter haritası üretilmiştir. Çalışmanın temelini, 2007 yılında MTA tarafindan hazırlanan ve 351 adet, kayma ve akma türü hareketlerin yer aldığı heyelan envanter haritası oluşturmaktadır. 2003-2013 y1llarını kapsayan arazi çalışmaları, 2004-2011 yılları arasındaki uydu görüntüleri ve 1954-2010 y1lları arasında alınan hava fotoğrafları kullanılarak heyelan envanter haritası güncellenmiştir. Çalışma, karadan ve denizden olmak üzere iki farklı şekilde gerçekleştirilmiştir. Özellikle Sinop-Gerze arasındaki kıyı kesime kayık ile ulaşılarak 829 adet heyelan belirlenmiştir. Deniz ile kıyı bağlantısı olmayan yerlerde meydana 
gelen heyelan poligonlarını üretmek için, gerek kayıkla gerekse denizin içinden yaklaşık ölçümler alınmıştır. Çalışma sahasında yol yapım çalışmaları sırasında birçok heyelan meydana gelmiş ve maddi hasara yol açmıştır (Şekil 7).

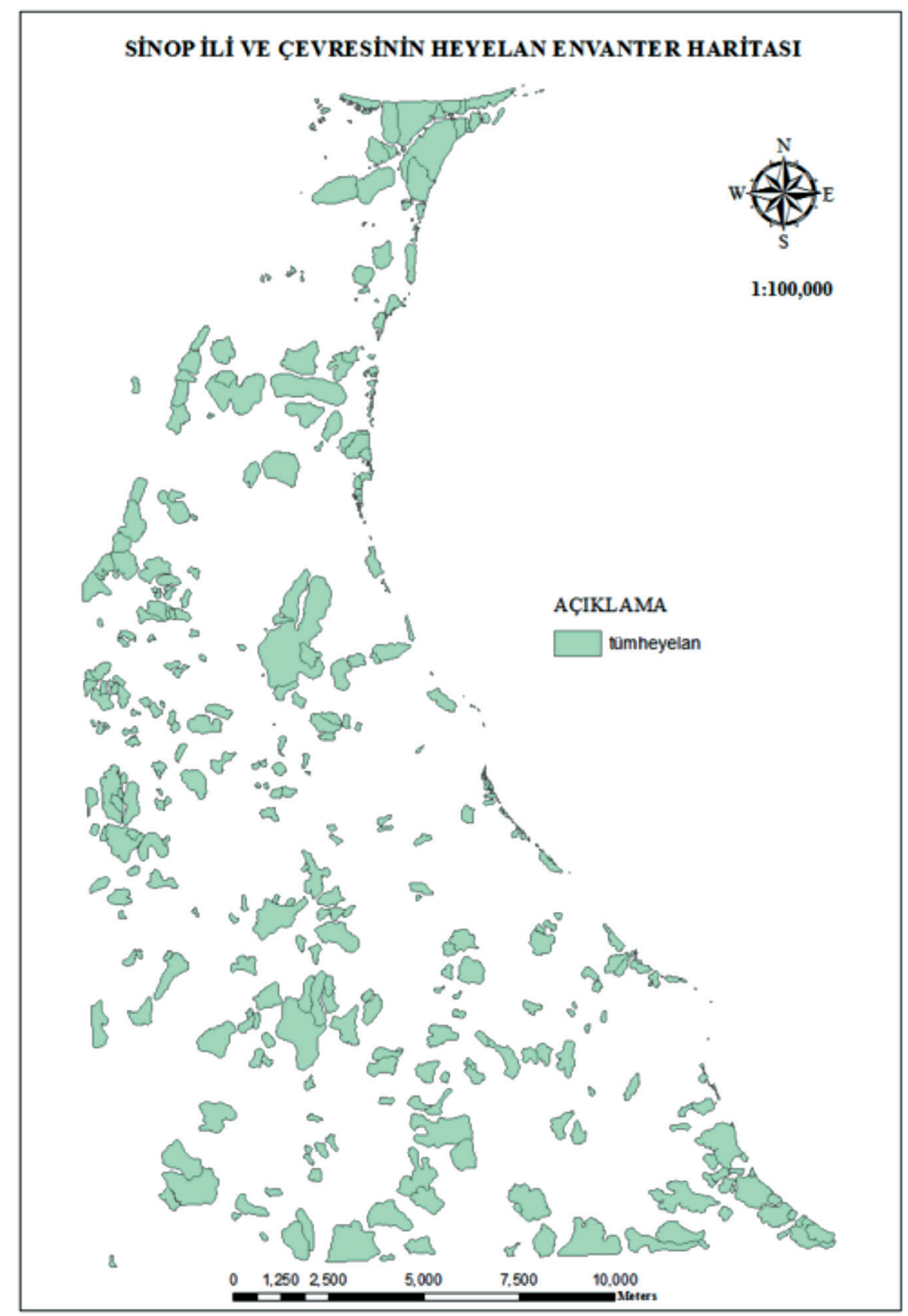

Şekil 6. Çalışma alanının heyelan envanter haritası.

Figure 6. The landslide inventory maps of the study area. 
Çellek, Bulut, Ersoy

Heyelanlar genel olarak aşağıdaki gibi alt gruplarda değerlendirilmiştir:

- Hareket tipine göre: Çalışma alanında dairesel kayma ve akma türü hareketler görülürken, sahil kesiminde düşme ve devrilme tarzı hareketlere rastlanmıştır.

- Aktivite durumuna göre: Aktif, duraklamış, reaktivite olmuş, bitmiş ve kalıntı heyelanlara rastlanmıştır.

- Derinliğine göre: Arazide çok sayıda heyelan gözlemlenmiş, gerek zamanın kısıtlı olması gerekse maddi olanakların yetersizliğinden dolayı ölçüm yapılamamıştır. Genel olarak kaymalar çok küçük ölçekte meydana geldiği
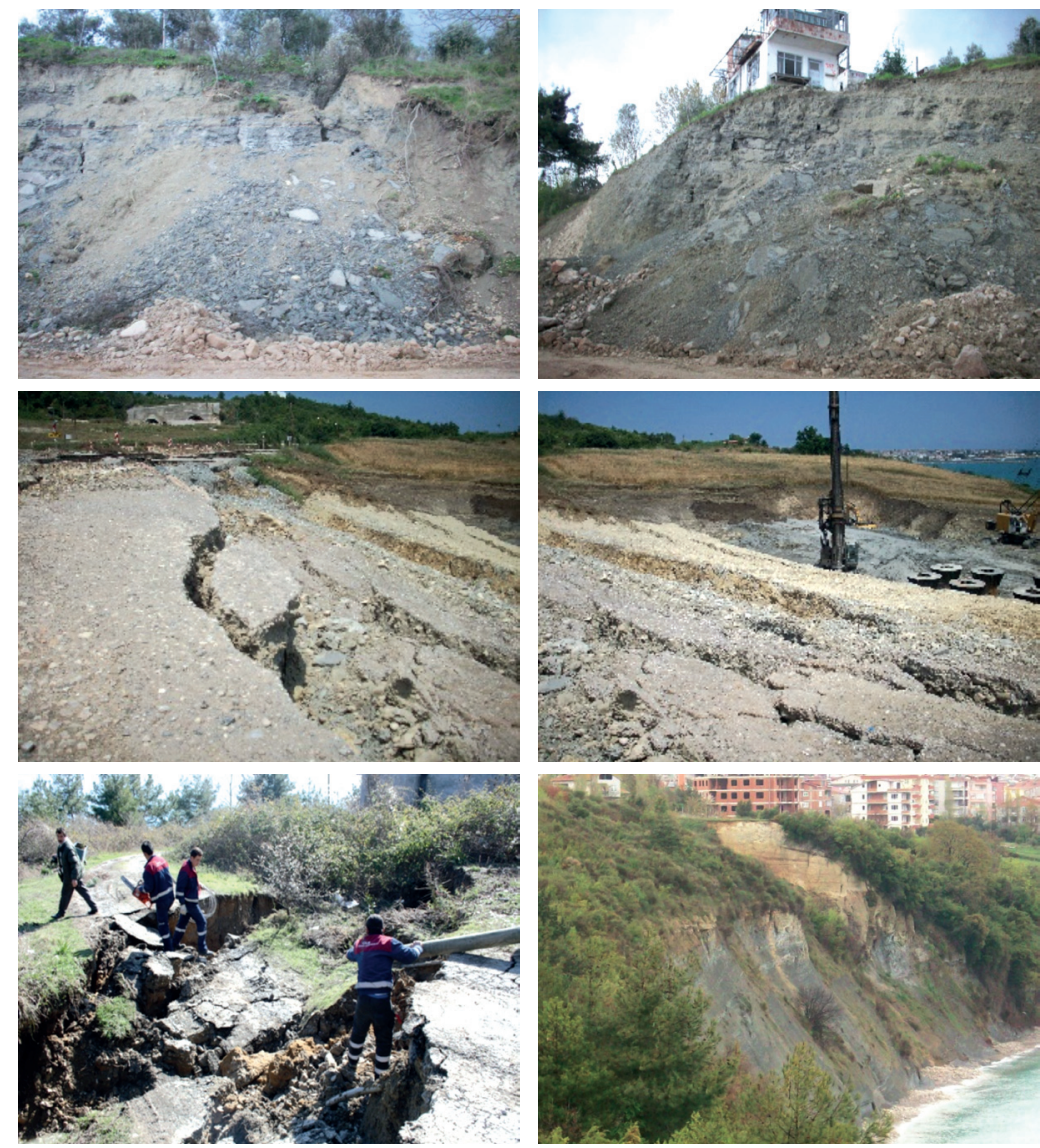

Şekil 7. Karadeniz sahil yolu yapımı aşamasında meydana gelen heyelanlara ait görüntüler.

Figure 7. Landslides occurred during the construction of the Blacksea coastal road. rastlanmıştır. malzemeden oluşmaktadır. gözlemlenmiştir.

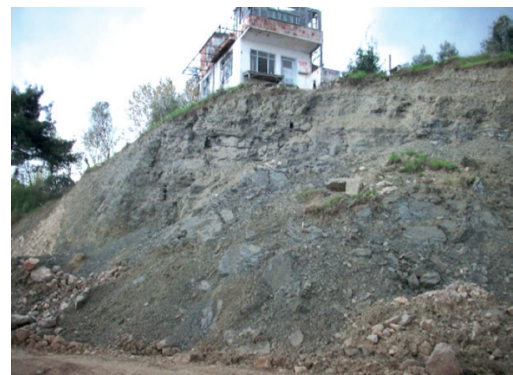

için bunlar sı̆̆ olarak değerlendirilmiştir. Arazide, derin olarak tanımlanan, büyüklükleri km ölçeğine kadar varan 5 adet büyük ölçekte heyelan tespit edilmiştir.

- Hareketin davranışına göre: İlerleyen, büyüyen ve genişleyen tarzda heyelanlara

- Malzeme türüne göre: Sahil kesiminde çoğunluğu kireçtaşı ve flişten oluşan kaya, zemin ve moloz türü malzemeye rastlanırken, saha büyük oranda zemin türü

- Hareket hızına göre: Hızlı ve yavaş akma 
Şekil 8'de alana ait farklı türde kütle hareketleri görülmektedir. Her bir parametreye ait haritalar, envanter haritası ile çakıştırılarak elde edilen haritalar ve yüzde olarak grafik dağılımları Şekil 9'da verilmiştir. Çizelge 4'te parametrelerin alt kriterlerinin heyelan duyarlılığına olan etkileri verilmiştir.

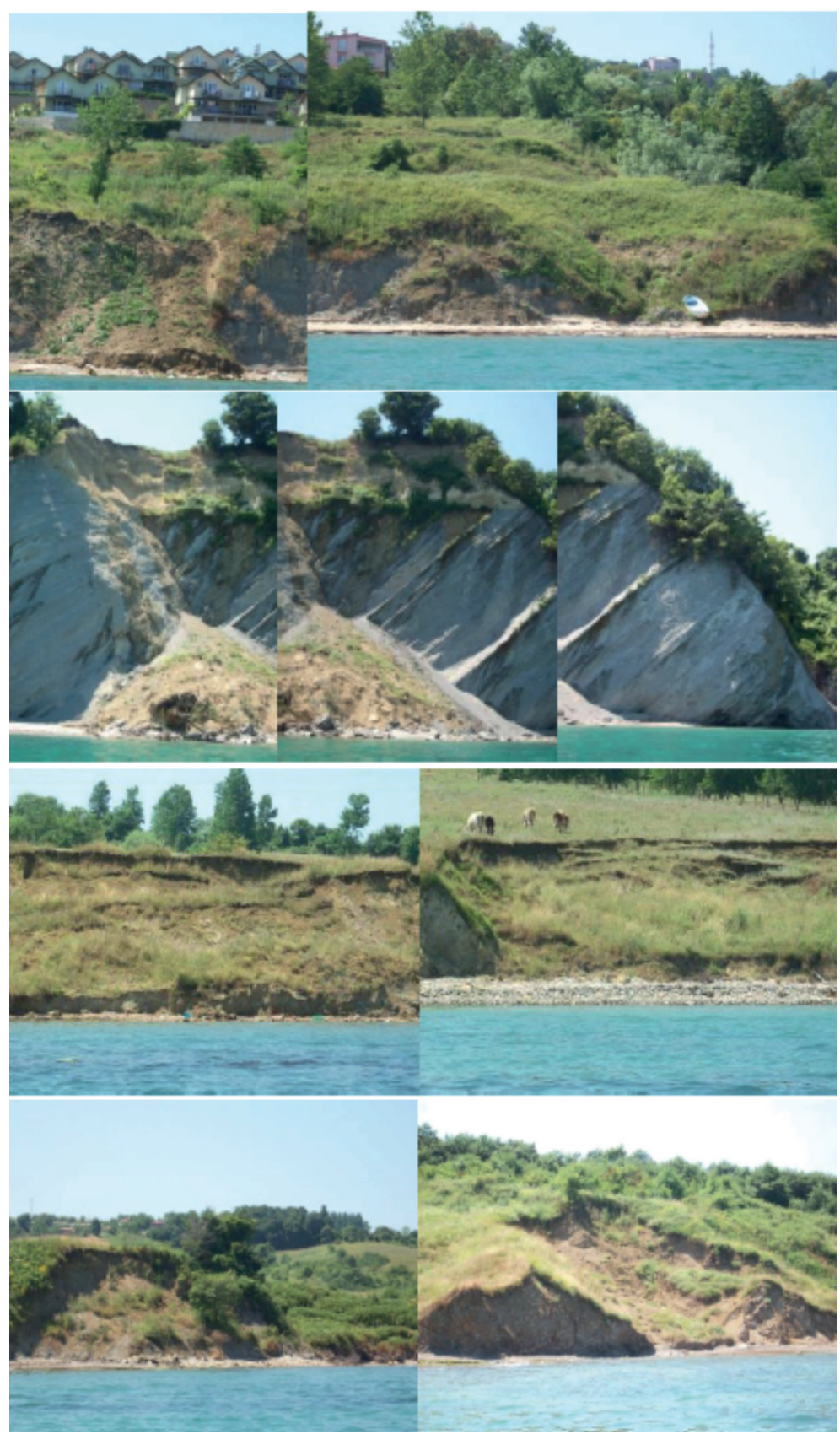

Şekil 8. Çalışma sahasına ait çeşitli heyelan görüntüleri.

Figure 8. Landslide photographs from the study area. 
Çellek, Bulut, Ersoy

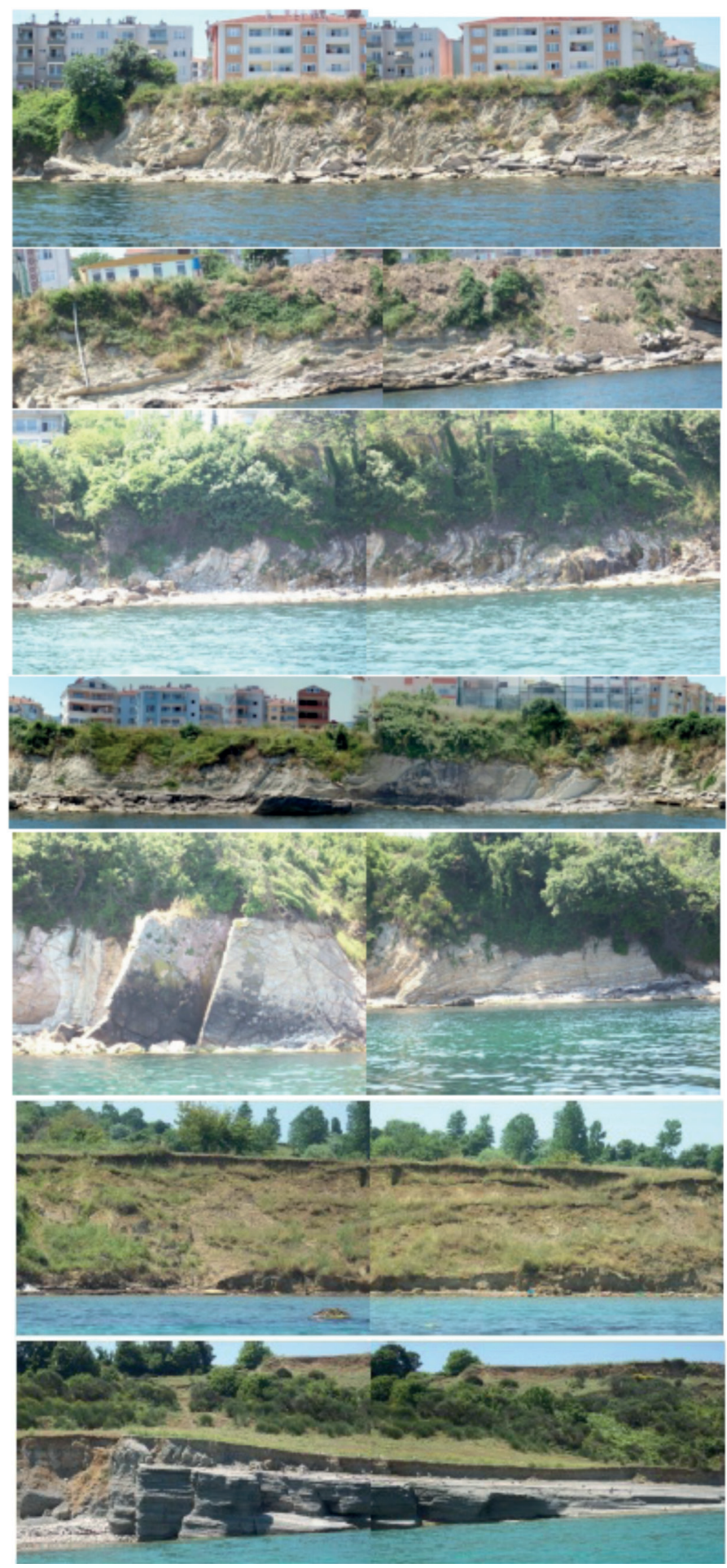

Şekil 8. (devamı)

Figure 8. (cont'd.) 
Çizelge 4. Parametre sınıfları ve heyelanlar arasındaki ilişkiler.

Table 4. Parameter classes and their relations with landslides.

\begin{tabular}{|c|c|c|c|c|c|}
\hline Parametre & Sinıf & $\% \mathrm{~A}$ & $\%$ B & $\mathbf{B} / \mathbf{A}$ & Heyelan Yoğunluğu \\
\hline \multirow{9}{*}{ Litoloji } & Sinop F. & 21,960 & 30,829 & 1,404 & 24,571 \\
\hline & Sarıkum F. & 6,195 & 3,908 & 0,631 & 11,041 \\
\hline & Plaj Çökeli & 0,174 & 0,067 & 0383 & 6,701 \\
\hline & Alüvyon & 11,299 & 0,340 & 0,030 & 0,526 \\
\hline & Kusuri F. & 15,526 & 13,299 & 0857 & 14,993 \\
\hline & Atbaşı $\mathrm{F}$. & 21,185 & 26,517 & 1,252 & 21,907 \\
\hline & Akveren F. & 21,647 & 25,037 & 1,157 & 20,243 \\
\hline & Hamsaros F. & 3,618 & 0,000 & 0,000 & 0,000 \\
\hline & Kale F. & 3,849 & 0,004 & 0,001 & 0,018 \\
\hline \multirow{12}{*}{ Ĕgim } & $0-5 \mathrm{~m}$ & 28,400 & 8,500 & 0,299 & 2,747 \\
\hline & $5-10 \mathrm{~m}$ & 29,640 & 38,920 & 1,313 & 12,064 \\
\hline & $10-15 \mathrm{~m}$ & 17,580 & 26,570 & 1,511 & 13,882 \\
\hline & $15-20 \mathrm{~m}$ & 10,130 & 13,470 & 1,339 & 12,309 \\
\hline & $20-25 \mathrm{~m}$ & 6,350 & 7,020 & 1,105 & 10,152 \\
\hline & $25-30 \mathrm{~m}$ & 3,960 & 3,210 & 0,810 & 7,443 \\
\hline & $30-35 \mathrm{~m}$ & 2,350 & 1,490 & 0,632 & 5,809 \\
\hline & $35-40 \mathrm{~m}$ & 1,120 & 0,510 & 0,457 & 4,207 \\
\hline & $40-45 \mathrm{~m}$ & 0,380 & 0,160 & 0,418 & 3,847 \\
\hline & $45-50 \mathrm{~m}$ & 0,080 & 0,050 & 0,644 & 5,922 \\
\hline & $50-55 \mathrm{~m}$ & 0,010 & 0,010 & 0,929 & 8,536 \\
\hline & $55-60 \mathrm{~m}$ & 0,000 & 0,000 & 1,424 & 13,083 \\
\hline \multirow{9}{*}{ Ĕ̆im Yönü (Bakı) } & Düz & 9,598 & 1,385 & 0.144 & 1.608 \\
\hline & Kuzey & 16,655 & 15,969 & 0.942 & 10.501 \\
\hline & Kuzeydoğu & 15,61 & 15,781 & 1.011 & 11.264 \\
\hline & Doğu & 12,91 & 16,644 & 1.289 & 14.364 \\
\hline & Güneydoğu & 11,856 & 13,694 & 1.150 & 12.819 \\
\hline & Güney & 7,454 & 9,030 & 1.197 & 13.336 \\
\hline & Güneybat1 & 5,613 & 5,663 & 1.009 & 11.241 \\
\hline & Bat1 & 7,734 & 9,262 & 1.198 & 13.344 \\
\hline & Kuzeybat1 & 12,476 & 12,901 & 1.034 & 11.523 \\
\hline
\end{tabular}


Çellek, Bulut, Ersoy

Çizelge 4. (devamı)

Table 4. (cont'd.)

\begin{tabular}{|c|c|c|c|c|c|}
\hline \multirow{11}{*}{ Yükseklik } & $0-100 \mathrm{~m}$ & 43.904 & 35.360 & 0.805 & 8.641 \\
\hline & $100-200 \mathrm{~m}$ & 20.032 & 21.190 & 1.058 & 11.351 \\
\hline & $200-300 \mathrm{~m}$ & 11.710 & 15.990 & 1.365 & 14.647 \\
\hline & $300-400 \mathrm{~m}$ & 6.871 & 8.730 & 1.270 & 13.629 \\
\hline & $400-500 \mathrm{~m}$ & 4.768 & 6.120 & 1.283 & 13.761 \\
\hline & $500-600 \mathrm{~m}$ & 4.304 & 6.280 & 1.459 & 15.657 \\
\hline & $600-700 \mathrm{~m}$ & 3.924 & 4.410 & 1.124 & 12.061 \\
\hline & $700-800 \mathrm{~m}$ & 2.687 & 1.520 & 0.565 & 6.059 \\
\hline & $800-900 \mathrm{~m}$ & 1.311 & 0.370 & 0.281 & 3.011 \\
\hline & $900-1000 \mathrm{~m}$ & 0.430 & 0.050 & 0.110 & 1.183 \\
\hline & $1000-1100 \mathrm{~m}$ & 0.059 & 0.000 & 0.000 & 0.000 \\
\hline \multirow{3}{*}{$\begin{array}{c}\text { Arazi } \\
\text { Sinıflaması }\end{array}$} & $\mathrm{Su}$ & 0.994 & 0.000 & 0.000 & 0.000 \\
\hline & Yerleşim & 60.243 & 98.000 & 1.628 & 97.000 \\
\hline & Orman & 38.762 & 2.000 & 0.049 & 3.000 \\
\hline \multirow{6}{*}{$\begin{array}{c}\text { Akarsuya } \\
\text { Yakınlık }\end{array}$} & $0-50 \mathrm{~m}$ & 1.654 & 0.456 & 0.276 & 5.097 \\
\hline & $50-100 \mathrm{~m}$ & 7.551 & 9.565 & 1.267 & 23.422 \\
\hline & $100-150 \mathrm{~m}$ & 14.526 & 13.824 & 0.952 & 17.595 \\
\hline & $150-200 \mathrm{~m}$ & 18.925 & 13.708 & 0.724 & 13.393 \\
\hline & $200-250 \mathrm{~m}$ & 18.608 & 20.690 & 1.112 & 20.558 \\
\hline & $>250 \mathrm{~m}$ & 38.732 & 41.758 & 1.078 & 19.935 \\
\hline \multirow{6}{*}{$\begin{array}{c}\text { Ana } \\
\text { Yola } \\
\text { Yakınlık }\end{array}$} & $0-50 \mathrm{~m}$ & 4.166 & 13.024 & 3.126 & 35.705 \\
\hline & $50-100 \mathrm{~m}$ & 8.331 & 9.759 & 1.171 & 13.379 \\
\hline & $100-150 \mathrm{~m}$ & 15.170 & 6.790 & 0.448 & 5.113 \\
\hline & $150-200 \mathrm{~m}$ & 10.826 & 25.860 & 2.389 & 27.281 \\
\hline & $200-250 \mathrm{~m}$ & 20.725 & 22.286 & 1.075 & 12.282 \\
\hline & $>250 \mathrm{~m}$ & 40.781 & 22.280 & 0.546 & 6.240 \\
\hline \multirow{3}{*}{$\begin{array}{c}\text { Yamaç } \\
\text { Eğriselliği }\end{array}$} & İç Bükey & 35.941 & 44.714 & 1.244 & 43.845 \\
\hline & Düz & 24.107 & 12.740 & 0.528 & 18.625 \\
\hline & Dış Bükey & 39.952 & 42.545 & 1.065 & 37.530 \\
\hline \multirow{6}{*}{$\begin{array}{c}\text { Yapısal } \\
\text { Unsurlara } \\
\text { Uzaklık }\end{array}$} & $0-50 \mathrm{~m}$ & 2.751 & 9.842 & 3.478 & 43.611 \\
\hline & $50-100 \mathrm{~m}$ & 13.639 & 10.596 & 0.777 & 9.469 \\
\hline & $100-150 \mathrm{~m}$ & 11.412 & 15.645 & 1.371 & 16.710 \\
\hline & $150-200 \mathrm{~m}$ & 25.851 & 5.683 & 0.220 & 2.680 \\
\hline & $200-250 \mathrm{~m}$ & 18.128 & 9.881 & 0.545 & 6.644 \\
\hline & $>250 \mathrm{~m}$ & 28.219 & 48.353 & 1.713 & 20.886 \\
\hline
\end{tabular}

A:Piksel Sayısı, B:Heyelanlı Piksel 


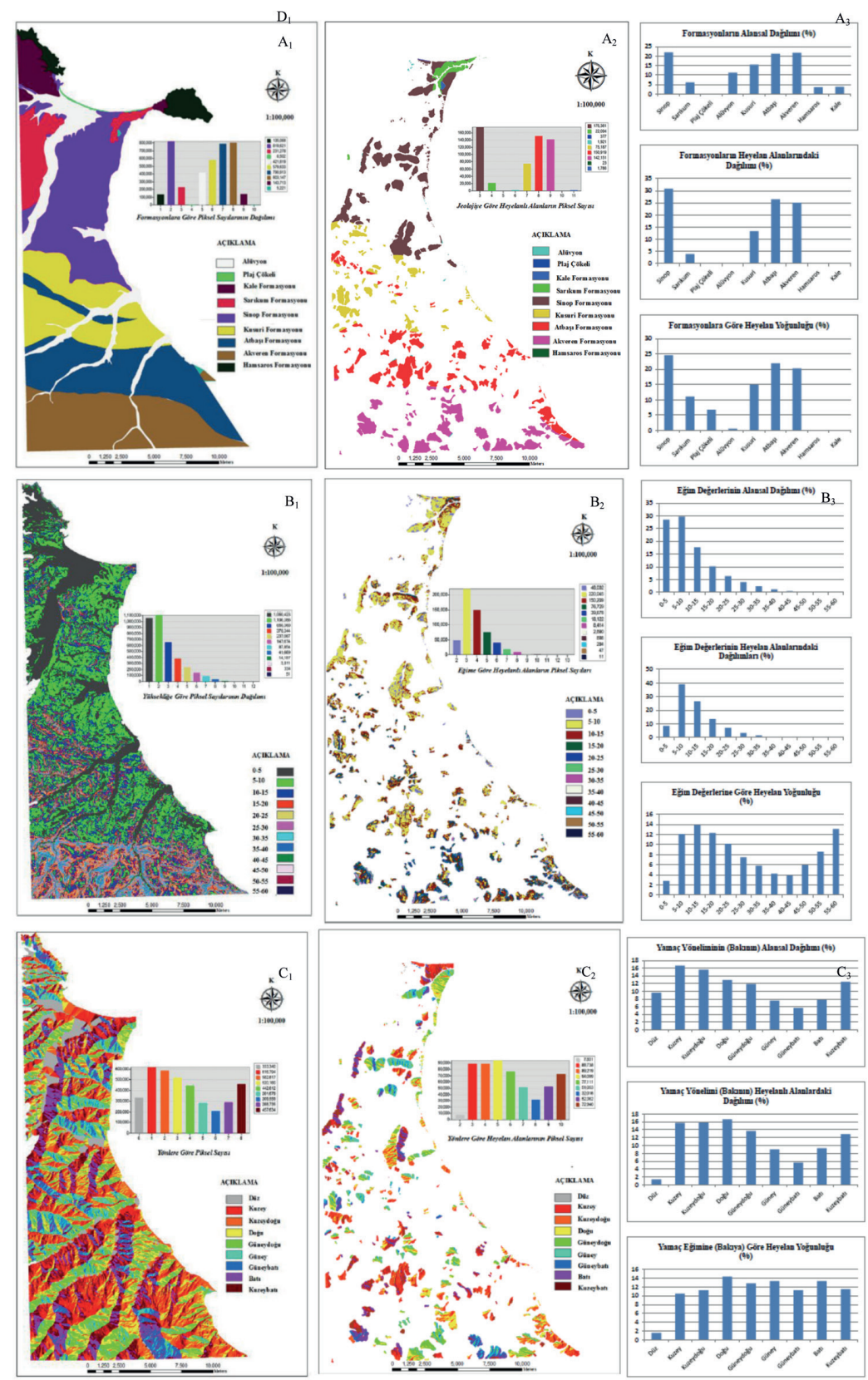

Şekil 9. $\quad A_{1}$. Litoloji parametresi, $A_{2}$. Heyelan poligonları ile çakıştırılmış litololoji parametresi, $A_{3}$. Litoloji parametresinin grafiksel görünümü, $\mathrm{B}_{1}$. Eğim parametresi, $\mathrm{B}_{2}$. Heyelan poligonları ile çakıştırılmış eğim parametresi, $\mathrm{B}_{3}$. Eğim parametresinin grafiksel görünümü, $\mathrm{C}_{1}$. Bakı parametresi, $\mathrm{C}_{2}$. Heyelan poligonları ile çakıştırılmış bakı parametresi, $\mathrm{C}_{3}$. Bak1 parametresinin grafiksel görünümü.

Figure 9. $A_{1}$. Lithology parameter $A_{2}$. Lithology map overlapped with landslide polygons, $A_{3}$. Graphical view of lithology parameter $B_{1}$. Slope parameter $B_{2}$. Slope map overlapped with landslide polygons, $B_{3}$. Graphical view of the slope parameter $C_{1}$. Aspect parameter $C_{2}$. Aspect map overlapped with landslide polygons, $C_{3}$. Graphical view of the aspect parameters. 
Çellek, Bulut, Ersoy

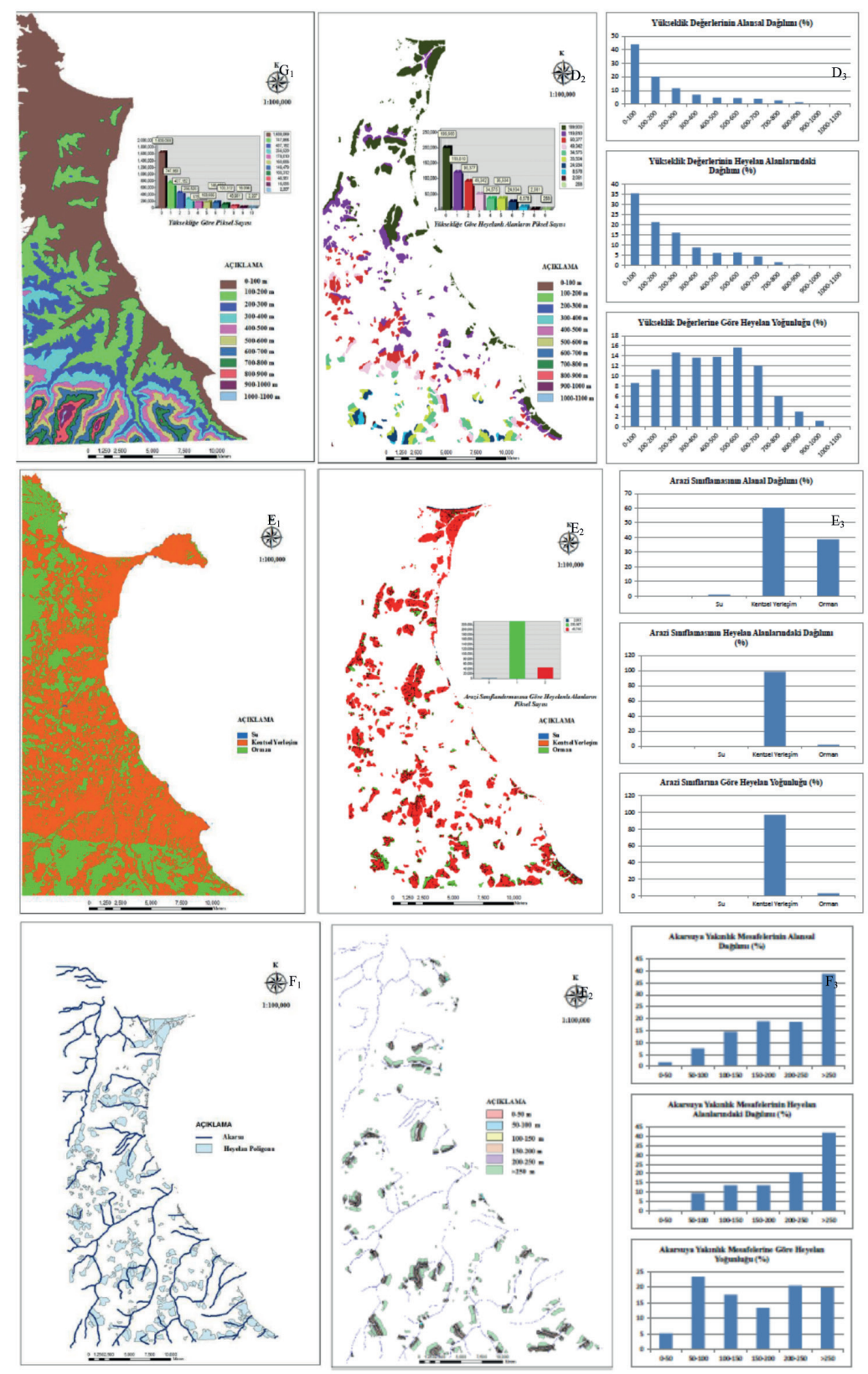

Şekil 9. (devamı) $D_{1}$. Yükseklik parametresi, $D_{2}$. Heyelan poligonları ile çakıştırılmış yükseklik parametresi, $D_{3}$. Yükseklik parametresinin grafiksel görünümü, $\mathrm{E}_{1}$. Arazi sınıfı parametresi, $\mathrm{E}_{2}$. Heyelan poligonları ile çakıştırılmış arazi sınıfı parametresi, $\mathrm{E}_{3}$. Arazi sınıfı parametresinin grafiksel görünümü, $\mathrm{F}_{1}$. Akarsuya yakınlık parametresi, $\mathrm{F}_{2}$. Heyelan poligonları ile çakıştırılmış akarsuya yakınlık parametresi, $F_{3}$. Akarsuya yakınlık parametresinin grafiksel görünümü

Figure 9. (cont'd). $D_{1}$. Elevation parameter $D_{2}$. Elevation map overlapped with landslide polygons, $D_{3}$. Graphical view of the parameter $E_{1}$. Land use parameter $E_{2}$. Map overlayed with terrain class parameter ranges, $E_{3}$. Graphical view of the land use parameter $F_{1}$. Distance to river parameter, $F_{2}$. Distance to river map overlapped with landslide polygons, $F_{3}$. Graphical view of distance to river parameter. 


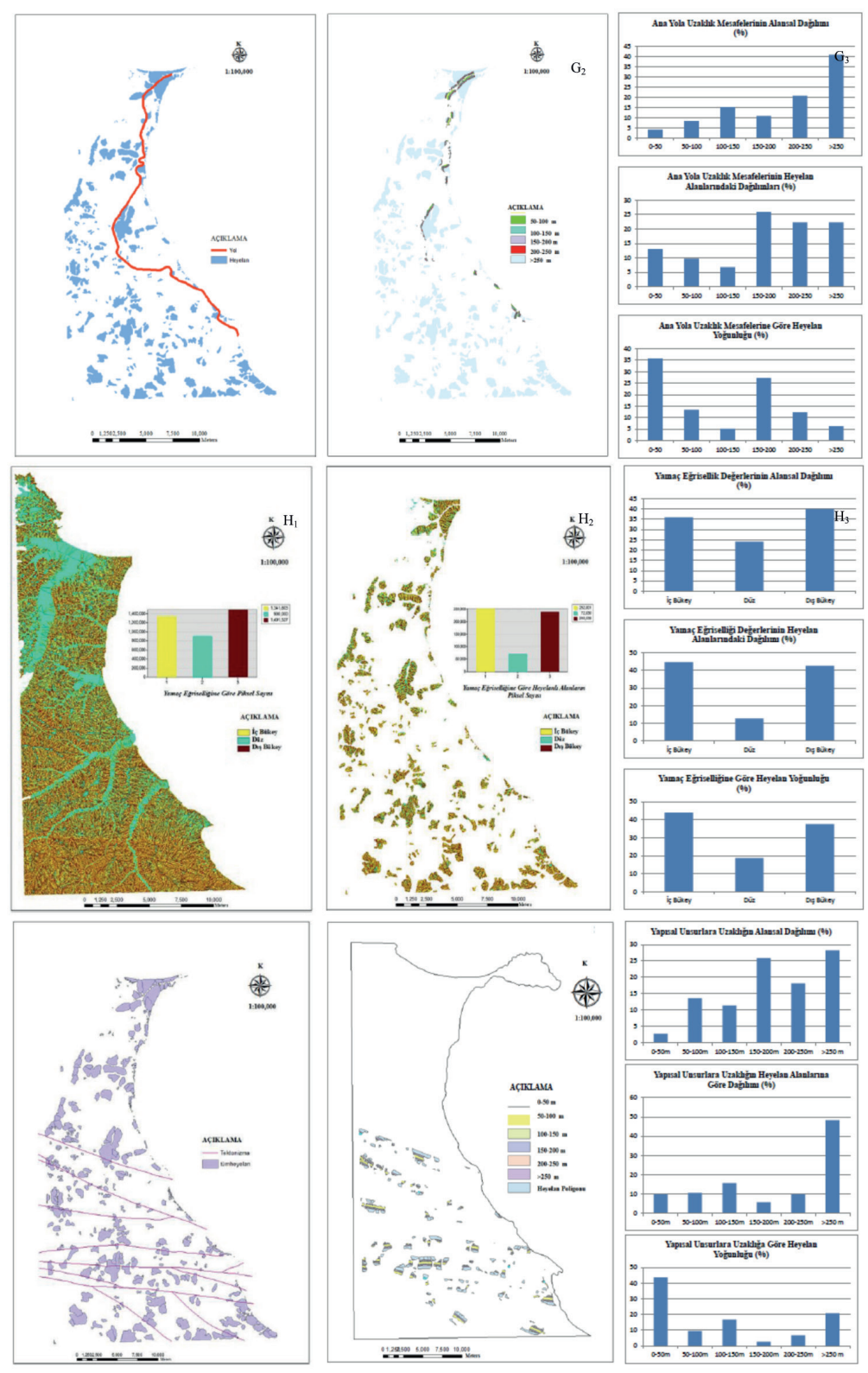

Şekil 9. (devamı) $\mathrm{G}_{1}$. Anayola Uzaklık parametresi, $\mathrm{G}_{2}$. Heyelan poligonları ile çakıştırılmış anayola Uzaklık parametresi, $\mathrm{G}_{3}$. Anayola Uzaklık parametresinin grafiksel görünümü, $\mathrm{H}_{1}$. Yamaç eğriselliği parametresi, $\mathrm{H}_{2}$. Heyelan poligonları ile çakıştırılmış yamaç eğriselliği parametresi, $\mathrm{H}_{3}$. Yamaç eğriselliği parametresinin grafiksel görünümü, I. Yapısal unsurlara uzaklık parametresi, $\mathrm{I}_{2}$. Heyelan poligonları ile çakıştırılmış yapısal unsurlara uzaklık parametresi, I. Yapısal unsurlara uzaklık parametresinin grafiksel görünümü

Figure 9. (cont'd). $G_{l}$. Distance to highway parameter $G_{2}$. Distance to highway parameter overlapped with landslide polygons, $G_{3}$. Graphical view of the distance to highway parameter $H_{1}$. Slope curvature parameter $H_{2}$. lope curvature map overlapped with landslide polygons $H_{3}$. Graphical view of the curvature of the slope parameter $I_{r}$. Distance to structural elements parameter $I_{2}$. From the structural element superimposed with a landslide polygons parameter $I_{3}$. Graphical view of the element parameter. 
Çellek, Bulut, Ersoy

\section{Tartışma ve Sonuçlar}

Çalışma alanı olarak, Karadeniz sahil yolu çalışmaları kapsamında 2014 yılında tamamlanan Sinop-Gerze karayolu güzergahı, sahil şeridi ve çevresi seçilmiştir. Duyarlılık haritasının hazirlanmasinda, envanter ve parametre seçiminde ve yöntem belirlemede literatür değerlendirmesi dikkate alınmıştır. Envanter hazırlanmasında MTA'nın 2007 yılında ürettiği 351 heyelanlı harita baz alınmış, 2013 yılına kadar olan süreçte, uydu ve hava görüntülerinin yanı sıra arazi çalışmaları ile desteklenerek 829 adet heyelan tespit edilmiştir. Özellikle sahil kesiminde kaya düşmesi, devrilme gibi kütle hareketlerine rastlanırken sahanın genelinde zemin malzemesi içinde dairesel kayma ve akma hareketleri gözlemlenmiştir. Ayrıca sahada, aktif heyelanların yanı sıra çok sayıda pasif ve reaktif hareketli kütlelere de rastlanmıştır. Parametreler seçilirken, literatürde en çok tercih edilen 9 parametre seçilmiş, AHP yöntemi, alan için uygun yöntem olarak seçilmiştir. Çalışma bölgesinde, son y1llarda meydana gelen heyelanların en büyük tetikleyicisinin yol yapımı çalışmaları olduğu düşünülmektedir. Aşırı yağışlı sezonun uzun sürmesi, litolojik özellikler ve suyun drenajındaki sorunlar da alanın heyelan duyarlılığını arttırmaktadır.

Son 15 y1llık dönemde yapılan çalışmalar incelendiğinde, özellikle son üç yılda AHP kullanımında artış olduğu belirlenmiştir. Bunun nedeni yöntemin kullanımının diğer yöntemlere göre daha basit olmasıdır. Çalışmaların \% 43'ünde tek yöntem olarak AHP kullanılırken, \% 57'sinde ise karşılaştırmalı yöntemler kullanılmıştır. Katmanların kendi içerisinde etki değerleri yukarıda ifade edilen hesaplamalarla bulunmuştur. Heyelan duyarlılık haritasının üretimi için katmanların birbiriyle olan ilişkilerinin belirlenmesi gerekmektedir. $\mathrm{Bu}$ çalışmada, heyelan duyarlılık haritalarının üretilmesine yönelik olarak arazi, laboratuvar ve masa başı çalışmaları sonucu elde edilen verilerle konumsal veri tabanı oluşturulmuştur. Raster veri modeline dönüştürülen veri katmanlarının, AHP ile yapılan hesaplamalar sonucunda hem veri katmanı bazında hem de alt kriterler bazında ağırlıkları belirlenerek analizleri yapılmıştır. $\mathrm{Bu}$ ağırlık değerlerinden büyük olanı, heyelan duyarlılığına olan etkinin daha fazla olduğunu işaret etmektedir (Çizelge 5). Bu analizlerin temeli, her katmandan aynı bir pikselin alacağ 1 özellik ile bunun matematiksel değeri ve heyelan duyarlılık haritasının üretimindeki etkisini belirlemeye dayanmaktadır.

Her bir katmanın alt kriterlerine karşılık gelen ağırlık değerleri (piksel faktör puanı) ait oldukları piksellere atanmış ve katmanların belirlenen ağırlık değerleri (piksel ağırlığı) piksel faktör puanıyla çarpılarak sonuç haritası üretilmiştir. Analiz sonucunda Sinop ve çevresi için heyelan duyarlılık haritası üretilmiştir. Yapılan analizler sonucunda, duyarlılık zonlarının çalışma alanındaki alan ve yüzde dağılımları belirlenmiştir (Çizelge 6). Çizelge 6 incelendiğinde, yörenin \% 10.77'sinin çok düşük, \% 10.59'unun düşük, \% 52.64'ünün orta, \% 25.64'ünün yüksek, \% 0.34'ünün ise çok yüksek derece duyarlı alanlardan oluştuğu belirlenmiştir. Üretilen heyelan duyarlılık haritasının güvenilirliğini test etmek için heyelan envanter haritası ve heyelan duyarlılık haritaları karşılaştırılmıştır. Bu karşılaştırmada, meydana gelmiş olan heyelanların gösterildiği heyelan envanter haritasındaki alanlar, heyelan duyarlılık haritası ile çakıştırılmıştır (Şekil 10). Daha 
sonra, mevcut heyelan alanlarının duyarlılık zonlarına göre dağılımları belirlenmiştir. Yapılan analizlerle mevcut heyelan alanlarının, üretilen heyelan duyarlılık haritasındaki yüksek ve çok yüksek duyarlı alanlarla olan ilişsisi araştırılmıştır. Pilot bölge olarak seçilen Gerze ve Sinop heyelan duyarlılık haritasında ortayüksek derecede duyarlı çıkmıştır.

Çizelge 5. Veri katmanları ve alt kriterlerin ağırlık değerleri.

Table 5. Data Layers and weight values of the sub-criteria.

\begin{tabular}{|c|c|c|c|}
\hline Katman & Alt Katman & Alt Katman Puanı & Katman Yüzde Önem Derecesi \\
\hline \multirow[t]{10}{*}{ BAKI } & & & 0,06 \\
\hline & Düz & 1 & \\
\hline & Kuzey & 3 & \\
\hline & Kuzeydoğu & 3 & \\
\hline & Doğu & 4 & \\
\hline & Güneydoğu & 2 & \\
\hline & Güney & 2 & \\
\hline & Güneybat1 & 2 & \\
\hline & Batı & 3 & \\
\hline & Kuzeybatı & 5 & \\
\hline \multirow[t]{10}{*}{ LİTOLOJİ } & & & 0,21 \\
\hline & Sinop Formasyonu & 5 & \\
\hline & Sarıkum Formasyonu & 2 & \\
\hline & Plaj Çökeli & 1 & \\
\hline & Alüvyon & 1 & \\
\hline & Kusuri Formasyonu & 4 & \\
\hline & Atbaşı Formasyonu & 5 & \\
\hline & Akveren Formasyonu & 5 & \\
\hline & Kale Formasyonu & 3 & \\
\hline & Hamsaros Formasyonu & 1 & \\
\hline \multirow[t]{3}{*}{ ARAZİ SINIFI } & & & 0,12 \\
\hline & Kentsel Yerleşim & 3 & \\
\hline & Orman & 2 & \\
\hline \multirow[t]{4}{*}{ EĞRİSELLİK } & & & 0,10 \\
\hline & İçbükey & 2 & \\
\hline & Düz & 1 & \\
\hline & Dişbükey & 3 & \\
\hline
\end{tabular}


Çellek, Bulut, Ersoy

Çizelge 5. (devamı)

Table 5. (cont'd.)

\begin{tabular}{|c|c|c|c|}
\hline \multirow[t]{13}{*}{ EĞì } & & & 0,16 \\
\hline & $0-5$ & 2 & \\
\hline & 05-010 & 2 & \\
\hline & 010-015 & 5 & \\
\hline & $15-20$ & 3 & \\
\hline & $20-25$ & 4 & \\
\hline & $25-30$ & 1 & \\
\hline & $30-35$ & 1 & \\
\hline & $35-40$ & 1 & \\
\hline & $40-45$ & 1 & \\
\hline & $45-50$ & 1 & \\
\hline & $50-55$ & 1 & \\
\hline & $55-60$ & 1 & \\
\hline \multirow[t]{11}{*}{ YÜKSEKLIK } & & & 0,10 \\
\hline & $0-100$ & 5 & \\
\hline & $100-200$ & 4 & \\
\hline & $200-300$ & 3 & \\
\hline & $300-400$ & 2 & \\
\hline & $400-500$ & 1 & \\
\hline & $500-600$ & 1 & \\
\hline & $600-700$ & 1 & \\
\hline & $700-800$ & 1 & \\
\hline & $800-900$ & 1 & \\
\hline & $900-1000$ & 1 & \\
\hline \multirow[t]{5}{*}{ YOL } & & & 0,20 \\
\hline & $0-250$ & 5 & \\
\hline & $250-500$ & 4 & \\
\hline & 500-1000 & 2 & \\
\hline & $1000>$ & 1 & \\
\hline \multirow[t]{2}{*}{ AKARSU } & & & 0,10 \\
\hline & Çakışan & 5 & \\
\hline \multirow[t]{2}{*}{ TEKTONIZMA } & & & 0,10 \\
\hline & Çakışan & 5 & \\
\hline
\end{tabular}


Çizelge 6. Çalışma alanında belirlenen heyelan duyarlılık sınıflarının yüzde dağılımları.

Table 6. Percentage distribution of landslide susceptibility classes.

\begin{tabular}{|c|c|c|}
\hline Duyarlılık Zonları & Piksel Sayısı & Yüzde Dağılım (\%) \\
\hline Çok düşük derece duyarlı alanlar & 218 & 10.77 \\
\hline Düşük derece duyarlı alanlar & 214.465 & 10.59 \\
\hline Orta derece duyarlı alanlar & $1.067,308$ & 52.64 \\
\hline Yüksek derece duyarlı alanlar & 519.766 & 25.66 \\
\hline Çok yüksek derece duyarlı alanlar & 7.870 & 0.34 \\
\hline
\end{tabular}

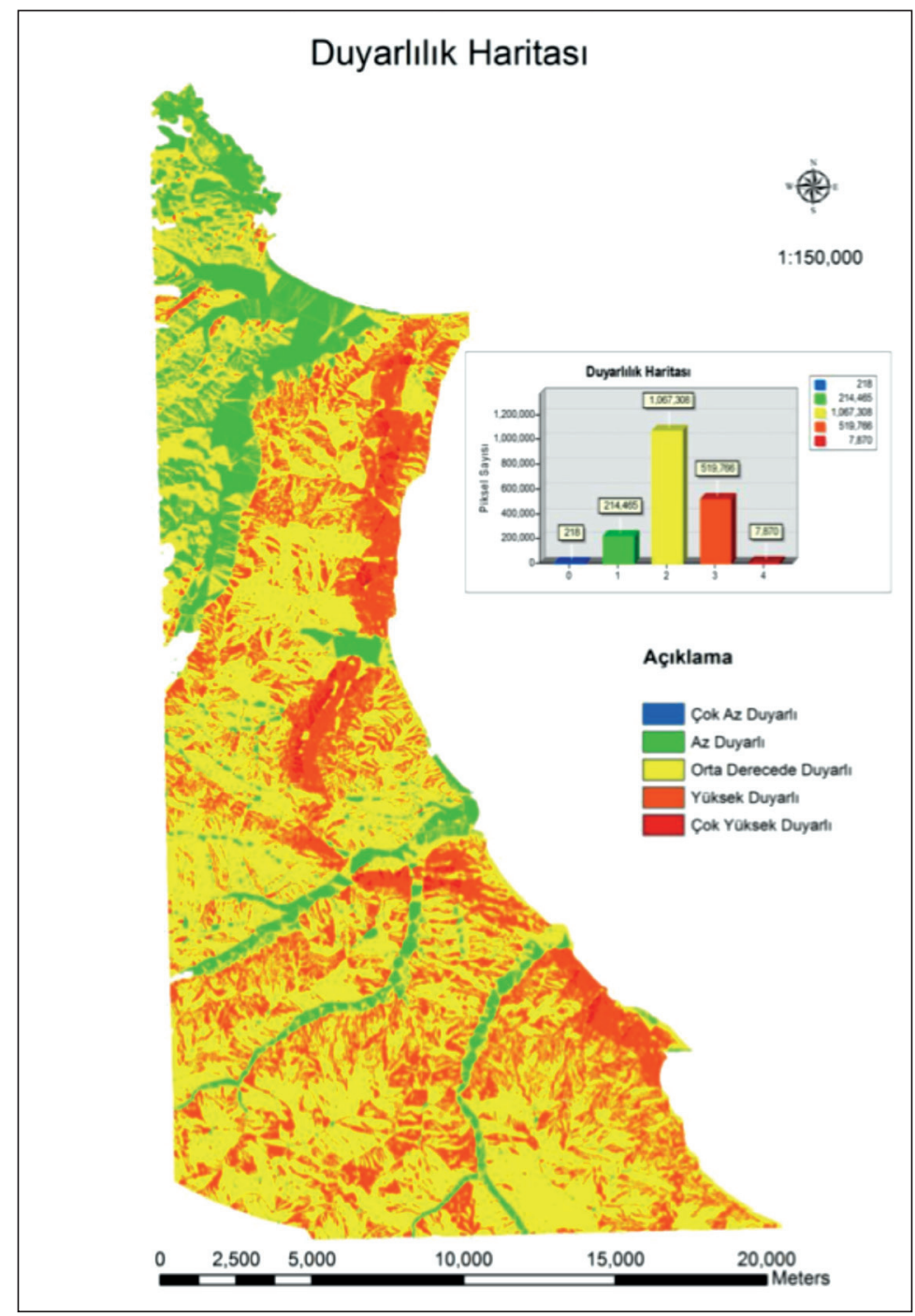

Şekil 10. Sinop ve çevresinin heyelan duyarlılık haritası.

Figure 10. Landslide susceptibility map of Sinop and its surroundings. 


\section{KAYNAKLAR}

Ahmed, B., 2014. Landslide susceptibility mapping using multi-criteria evaluation techniques in Chittagong Metropolitan Area, Bangladesh. Landslides, 12 (6), 1077-1095.

Akgun, A., 2012. A comparison of landslide susceptibility maps produced by logistic regression, multi-criteria decision, and likelihood ratio methods: a case study at İzmir, Turkey. Landslides, 9, 93-106.

Akgun, A., Bulut, F., 2007. GIS-based landslide susceptibility for Arsin-Yomra (Trabzon, North Turkey) region. Environmental Geology, 51, 1377-1387.

Akgun, A., Turk. N., 2010. Landslide susceptibility mapping for Ayvalik (Western Turkey) and its vicinity by multicriteria decision analysis. Environmental Earth Sciences, 61, 595-611.

Akgun, A., Dag, S., Bulut F., 2008. Landslide susceptibility mapping for a landslide-prone area (Fndikli, NE of Turkey) by likelihood-frequency ratio and weighted linear combination models. Environmental Geology, 54, 1127-1143.

Aktimur, H. T.,Yurdakul, M. E., Sönmez, M., Karabıyıklığlu, N., Kozan, T., Tekin, Z., Canpolat, M., 1993. Sinop İlinin Arazi Kullanım Potansiyeli, MTA Genel Müdürlüğü Jeoloji Etütleri Dairesi, Ankara.

Althuwaynee, O. F., Pradhan, B., 2014. Ensemble of Data-Driven EBF model with Knowledge Based AHP Model for Slope Failure Assessment in GIS Using Cluster Pattern Inventory. FIG Congress Engaging the Challenges - Enhancing the Relevance Kuala Lumpur, Malaysia 16-21 June.

Althuwaynee, O. F., Pradhan, B., Park, H. J., Lee, J. H., 2014. A novel ensemble bivariate statistical evidential belief function with knowledge-based analytical hierarchy process and multivariate statistical logistic regression for landslide susceptibility mapping. Catena, 114, 21-36.
Ayalew, L., Yamagishi, H., Marui, H., Kanno, T., 2005. Landslides in Sado Island of Japan: Part II. GISbased susceptibility mapping with comparisons of results from two methods and verifications. Engineering Geology, 81, 432- 445.

Bagherzadeh, A., Daneshvar, M. R. M., 2013. Mapping of landslide hazard zonation using GIS at Golestan watershed, northeast of Iran. Arabian Journal of Geoscience, 6, 3377-3388.

Barka, A., Sütçü, Y. F., Tekin, F., Gedik, İ., Karabıyıkoğlu, M., Saraç, G., Önal, Ö., Arel, E., Özdemir M., 1983. Sinop Yarımadası'nın jeolojisi ve tektonik evrimi, Türkiye Jeoloji Kurultayı Bülteni.

Barredo, J. I., Benavides, A., Hervh, J., Van Westen, C. J., 2000. Comparing heuristic landslide hazard assessment techniques using GIS in the Tirajana basin, Gran Canaria Island, Spain. International Journal of Applied Earth Observation and Geoinformation, 2 (1), 9-23.

Barredo, J. I., Hervh, J., Lomoschitz, A., Benavides, A., Van Westen, C. J., 2010. Landslide Hazard Assement using Gis and multicriteria evaluation techniques in the Tirajana basin, Gran Canaria Island, Spain. RUNOUT Project, funded by the European Comission under contract no.ENV4CT97-0527 with DG XII, within FP4 Enviroment and Climate Programme.

Bathrellos, G. D., Gaki-Papanastassiou, K., Skilodimou, H. D., Skianis, G. A., Chousianitis, K. G., 2013. Assessment of rural community and agricultural development using geomorphological-geological factors and GIS in the Trikala prefecture (Central Greece). Stochastic Environmontal Research and Risk Assessment, 27, 573-588.

Bhatt, B. P., Awasthi, K. D., Heyojoo, B. P., Silwal, T., Kafle, G., 2013. Using geographic information system and analytical hierarchy process in landslide hazard zonation. Applied Ecology and Environmental Sciences, 1 (2), 14-22. 
Calligaris, C., Poretti, G., Tariq, S., Melis, M. T., 2013. First steps towards a landslide inventory map of the Central Karakoram National Park. European Journal of Remote Sensing, 46, 272-287.

Castellanos Abella, E. A., Van Westen, C. J., 2007. Generation of a landslide risk index map for Cuba using spatial multi-criteria evaluation. Landslides, 4 (4), 311-325.

Chalkias C., Ferentinou M., Polykretis C., 2014. GISBased Landslide Susceptibility Mapping on the Peloponnese Peninsula, Greece. Geosciences, 4, 176-190.

Chen, W., Li, W., Hou, E., Li, X., 2014. GIS-based landslide susceptibility mapping using analytical hierarchy process (AHP) and certainty factor (CF) models for the Baozhong region of Baoji City, China. Environmental Earth Sciences, DOI 10.1007/s12665-014-3749-9.

Chingkhei, R. K., Shiroyleima, A., Robert Singh, L., Kumar, A., 2013. Landslide Hazard Zonation in $\mathrm{NH}-1 \mathrm{~A}$ in Kashmir Himalaya, India. International Journal of Geosciences, 4, 1501-1508.

Chuan, T., Jing, Z., Jingtao, L., 2009. Emergency assessment of seismic landslide susceptibility: a case study of the 2008 Wenchuan earthquake affected area. Earthquake Engineering and Engineering Vibration, 8 (28), 207-217.

Çellek, S., 2013. Sinop-Gerze yöresinin heyelan duyarlılık analizi. Karadeniz Teknik Üniversitesi Fen Bilimleri Enstitüsü, Trabzon, Doktora Tezi, $271 \mathrm{~s}$ (yayımlanmış).

Daneshvar, M. R. M., 2014. Landslide susceptibility zonation using analytical hierarchy process and GIS for the Bojnurd region, northeast of Iran. Landslides, 11, 1079-1091.

Daneshvar, M. R. M., Bagherzadeh, A., 2011. Landslide hazard zonation assessment using GIS analysis at Golmakan Watershed, northeast of Iran. Frontiers of Earth Science, 5 (1), 70-81.
Demir, G., Aytekin, M., Akgun, A., Ikizler, S. B., Tatar, O., 2013. A comparison of landslide susceptibility mapping of the eastern part of the North Anatolian Fault Zone (Turkey) by likelihood-frequency ratio and analytic hierarchy process methods. Natural Hazards, 65, 14811506.

Diop, S., 2012. An Overview of Landslide Occurrence, Inventorization and Susceptibility Mapping in South Africa. Landslide Risk Assessments for Decision Making, Council for Geoscience, UR Forum Mapping Global Risk, July 2-6/ Cape Town, South Africa.

Domakinis, C., Oikonomidis, D., Astaras, T., 2008. Landslide mapping in the coastal area between the Strymonic Gulf and Kavala (Macedonia, Greece) with the aid of remote sensing and geographical information systems. International Journal of Remote Sensing, 29 (23), 6893-6915.

Esmali, Y., Ahmadi, H., 2003. Using GIS \& RS in Mass Movements Hazard Zonation -A Case Study in Germichay Watershed, Ardebil, Iran. Map India Disaster Management Conference.

Ercanoglu, M., Kasmer, O., Temiz, N., 2008. Adaptation and comparison of expert opinion to analytical hierarchy process for landslide susceptibility mapping. Bulletin of Engineering Geology and Environment, 67, 565-578.

Feizizadeh, B., Blaschke, T., 2014. An uncertainty and sensitivity analysis approach for GISbased multicriteria landslide susceptibility mapping. International Journal of Geographical Information Science, 28 (3), 610-638.

Feizizadeh, B., Blaschke, T., Nazmfar, H., 2014a. GIS-based ordered weighted averaging and Dempster-Shafer methods for landslide susceptibility mapping in the Urmia Lake Basin, Iran. International Journal of Digital Earth, 7 (8), 688-708. 
Çellek, Bulut, Ersoy

Feizizadeh, B., Jankowski, P., Blaschke, T., 2014b. A GIS based spatially-explicit sensitivity and uncertainty analysis approach for multi-criteria decision analysis. Computers \&Geosciences, 64, $81-95$.

Feizizadeh, B., Jankowski, P., Blaschke, T., 2013a. A Spatially Explicit Approach for Sensitivity and Uncertainty Analysis of GIS-Multicriteria Landslide Susceptibility Mapping. ÖAW Verlag, Wien. eISBN 978-3-7001-7438-7, doi:10.1553/ giscience2013s157.

Feizizadeh, B., Blaschke, T., 2013. GIS-multicriteria decision analysis for landslide susceptibility mapping: comparing three methods for the Urmia lake basin, Iran. Natural Hazards, 65, 2105-2128.

Feizizadeh, B., Blaschke, T., Roodposhti, M. S., 2013b. Integrating GIS Based Fuzzy Set Theory in Multicriteria Evaluation Methods for Landslide Susceptibility Mapping. International Journal of Geoinformatics, 9 (3), 49-57.

Feizizadeh, B., Blaschke, T., Nazmfar, H., Rezaei Moghaddam, M. H., 2013c. Landslide susceptibility mapping for the Urmia Lake basin, Iran: A multi-criteria evaluation approach using GIS. International Journal of Environmental Research, 7 (2), 319-336.

Feizizadeh, B., Blaschke, T., Rafiq, L., 2010. G1sBased Landslide Susceptability Mapping: A Case Study In Bostan Abad County, Iran.http://ispace. researchstudio.at/sites/ispace.researchstudio.at/ files/239_full.pdf

Gaprindashvili, G., 2011. Landslide hazard assessment in Georgia. Report on the 1st project of AES Geohazards Stream, Faculty of GeoInformation Science and Earth Observation (ITC) of the University of Twente, Enschede, The Netherlands.

Ghosh, S., Carranza, E. J. M., Van Westen, C. J., Jetten, V. G., Bhattacharya, D. N., 2011. Selecting and weighting spatial predictors for empirical modeling of landslide susceptibility in the Darjeeling Himalayas (India), Geomorphology, 131, 35-56.

Gorsevski, P. V., Jankowski, P., Gessler, P. E., 2006. An heuristic approach for mapping landslide hazard by integrating fuzzy logic with analytic hierarchy process. Control and Cybernetics, 35 (1), 121-146.

Gorsevski, P. V., Jankowski, P., 2010. An optimized solution of multi-criteria evaluation analysis of landslide susceptibility using fuzzy sets and Kalman filter. Computers \& Geosciences, 36, 1005-1020.

Guoqing, Y., Haibo, Y., Zhizong, T., Baosen, Z., 2011. Landslide Risk Analysis of Miyun Reservoir Area Based on RS and GIS. Procedia Environmental Sciences, 10, $2567-2573$.

Habibi, A., 2014. Landslide hazard zonation for determination appropriate regions with AHP model in dry areas of Iran Khuzestan (Iran). Alireza Habibi International Journal of Forest, Soil and Erosion (IJFSE), 4 (1), 228-826.

Hasekiogulları, G. D., Ercanoglu, M., 2012. A new approach to use AHP in landslide susceptibility mapping: a case study at Yenice (Karabuk, NW Turkey). Natural Hazards, 63, 1157-1179.

Ilanloo, M., Soltani, Y. M., Jamnani, L. E., Ebrahimi, L., Myrfkhray, S., B. 2014. Earthquake Hazard Zonation using Analytical Hierarchy Method (AHP): A Case Study of Kelardasht. Geodynamics Research International Bulletin, 2 (4), 148-155.

Intarawichian, N., Dasananda, S., 2010. Analytical Hierarchy process for landslide susceptibility mapping in Lower Mae Chaem Watershed, Northern Thailand. Suranaree Journal of Science and Technology, 17 (3), 277-292.

Ivanova, E., 2014. Landslide susceptibility mapping using Frequency Ratio and Analytic Hierarchy Process (AHP): Comparative study of two areas 
in Bulgaria. International Conference Analysis and Management of Changing Risks for Natural Hazards, 18-19 November, Padua, Italy.

Jin, K. C., Oh, C. Y., Chul, C. U., 2010 The comparative research of landslide susceptibility mapping using FR, AHP, LR, ANN. Journal of Korean Society for Geospatial Information System, 9, 13-20.

Kamp, U., Growley, B. J., Khattak, G. A., Owen, L. A., 2008. GIS-based landslide susceptibility mapping for the 2005 Kashmir earthquake region. Geomorphology, 101, 631-642.

Kavzoglu, T., Sahin, E. K., Colkesen, I., 2014. Landslide susceptibility mapping using GISbased multi-criteria decision analysis, support vector machines, and logistic regression. Landslides, 11, 425-439.

Kayastha, P., Dhital, M. R., DeSmedt, F., 2013. Application of the Analytical Hierarchy Process (AHP) for landslide susceptibility mapping: A case study from the Tinau watershed, west Nepal. Computers \& Geosciences, 52, 398-408.

Khezri, S., 2011. Landslide susceptibility in the Zab Basin, northwest of Iran. Procedia Social and Behavioral Sciences, 19, 726-731.

Komac, M., 2003. Geohazard map of the central Slovenia - the mathematical approach to landslide prediction. Geologija, 46 (2), 367-372.

Komac, M., 2005. A landslide susceptibility model using the Analytical Hierarchy Process method and multivariate statistics in perialpine Slovenia. Geomorphology, 74, 17-28.

Kornejady, A., Kohzad, H., Sarparast, M., Khosravi, G., Mombeini, M., 2014. Performance assessment of two "LNRF" and "AHP-Area Density" models in landslide susceptibility zonation. Journal of Life Science and Biomedicine, 4 (3), 169-176.

Ladas, I., Fountoulis, I., Mariolakos, I., 2007. Using GIS \& Multicriteria Decision Analysis in landslide susceptibility mapping -A case study in Messinia Prefecture area (Sw Peloponnesus, Greece). Bulletin of the Geological Society of Greece, , Proceedings of the 11th International Congress, Athens.

Ma, F., Wang, J., Yuan, R., Zhao, H., Guo, J., 2013. Application of analytical hierarchy process and least-squares method for landslide susceptibility assessment along the Zhong-Wu natural gas pipeline, China. Landslides, 10, 481-492.

Margarint, M. C., Niculita, M., 2014. Comparison and validation of Logistic Regression and Analytic Hierarchy Process models of landslide susceptibility in monoclinic regions. A case study in Moldavian Plateau, N-E Romania. EGU General Assembly, Geophysical Research Abstracts, 16, 6371.

Marjanović, M., 2009a. Landslide susceptibility mapping with Support vector machine algorithm The GI-Forum Program Committee framework of Methods of artificial intelligence in GIS, a project of Czech Republic Grant Agency (CR GA 205/09/079).

Marjanović, M., 2009b. Landslide Susceptıbility Modellıng: A Case Study On Fruška Gora Mountain, Serbia. Geomorphologia Slovaca Et Bohemica, 9 (1), 29-42.

Marjanoviç, M., Bajat, B., Kovaçeviç, M., 2009. Landslide susceptibility assessment with machine learning algorithms, International Conference on Intelligent Networking and Collaborative Systems, IEEE Computer Society, 273-278.

Marjanović, M., Abolmasov, B., Đurıć, U., Bogdanović, S., 2013. Impact of geoenvironmental factors on landslide susceptibility using an AHP method: A case study of Fruška Gora Mt., Serbia. Annales Geologiques De La Penınsule Balkanıque, 74, 91-100. 
Çellek, Bulut, Ersoy

Mezughi, T. H., Akhir, J. M., Rafek, A. G., Abdullah, I., 2012. Analytical Hierarchyy Process Method for mapping landslide susceptibility to an area along the E-W Highway (Gerik-Jeli), Malaysia. Asian Journal of Earth Sciences, 5 (1), 13-24.

Mondal, S., Maiti, R., 2013. Integrating the Analytical Hierarchy Process (AHP) and the Frequency Ratio (FR) model in landslide susceptibility mapping of Shiv-khola Watershed, Darjeeling Himalaya. International Journal of Disaster Risk Science, 4 (4), 200-212.

Mondal, S., Maiti, R., 2012. Landslide susceptibility analysis of Shiv-Khola Watershed, Darjiling: A remote sensing \& GIS based analytical hierarchy process (AHP). Journal of the Indian Society of Remote Sensing, 40 (3), 483-496.

Moradi, S., Rezaei, M., 2014. A GIS-based comparative study of the analytic hierarchy process, bivariate statistics and frequency ratio methods for landslide susceptibility mapping in part of the Tehran metropolis, Iran. Geopersia, 4 (1), 45-61.

Moradi, M., Bazyar, M. H., Mohammadi, Z., 2012. GIS-Based Landslide Susceptibility Mapping by AHP Method, A Case Study, Dena City, Iran. Journal of Basic and Applied Scientific Research, 2 (7), 6715-6723.

Mustafa, I. S., Din, N. M., Ismail, A., Omar, R. C., Khalid, N. H. N., 2013. Antenna placement for landslide monitoring using analytical hierarchy process (AHP) and Geographical Information System (GIS). IEEE Symposium on Wireless Technology and Applications (ISWTA), September 22-25, Kuching, Malaysia.

Niu, F., Luo, J., Lin, Z., Liu, M., Yin, G., 2014. Thaw-induced slope failures and susceptibility mapping in permafrost regions of the QinghaiTibet Engineering Corridor, China. Natural Hazards, 74, 1667-1682.

Othman, A. N., Mohd, W. M. N. W., Noraini, S,. 2014. Accuracy assessment of landslide prediction models. 8th International Symposium of the Digital Earth (ISDE8) IOP Publishing, IOP Conference Series, Earth and Environmental Science, 18, 1-6.

Ouri, A. E., Amirian, S., 2009. Landslide hazard zonation using MR and AHP methods and GIS techniques in Langan watershed, Ardabil, Iran. International Conference on ACRS 2009, Beijing,China.https://www.researchgate.net/ publication/266501883_Landslide_hazard_ zonation_using_MR_and_AHP_methods and_GIS_techniques_in_Langan_watershed_ Ardabil_Iran

Ownegh, M., 2004. Assessing the applicability of Australian landslide databases for hazard management. ISCO - 13th International Soil Conservation Organisation Conference Brisbane, July.

Park, S., Choi, C., Kim, B., Kim, J., 2013. Landslide susceptibility mapping using frequency ratio, analytic hierarchy process, logistic regression, and artificial neural network methods at the Inje area, Korea. Environmental Earth Sciences, 68, 1443-1464.

Pourghasemi, H. R., Pradhan, B., Gokceoglu, C., 2012b. Application of fuzzy logic and analytical hierarchy process (AHP) to landslide susceptibility mapping at Haraz watershed, Iran. Natural Hazards, 63, 965-996.

Pourghasemi, H. R., Pradhan, B., Gokceoglu, C., Moezzi, K. D., 2012a. Landslide susceptibility mapping using a Spatial Multi Criteria Evaluation Model at Haraz Watershed, Iran (Chapter 2). Terrigenous Mass Movements, Springer-Verlag Berlin Heidelberg, DOI: 10.1007/978-3-642 25495-6-2.

Pourghasemi, H. R., Moradi, H. R., Fatemi Aghda, S. M., 2013. Landslide susceptibility mapping by binary logistic regression, analytical hierarchy process, and statistical index models and assessment of their performances. Natural Hazards, 69, 749-779. 
Pourghasemi, H. R., Moradi, H. R., Fatemi-Aghda, S. M., Gokceoglu, C., Pradhan, B., 2014. GISbased landslide susceptibility mapping with probabilistic likelihood ratio and spatial multicriteria evaluation models (North of Tehran, Iran). Arabian Journal of Geosciences, 7, 18571878.

Prabu, S., Ramakrishnan, S. S., 2009. Combined use of Socio Economic Analysis, Remote Sensing and GIS Data for landslide hazard mapping using ANN. Journal of the Indian Society of Remote Sensing, 37, 409-421.

Quan, H. C., Lee, B. G., 2012. GIS-Based landslide susceptibility mapping using Analytic Hierarchy Process and Artificial Neural Network in Jeju (Korea). KSCE Journal of Civil Engineering, 16 (7), 1258-1266.

Qiu, D., Niu, R., Zhao, Y., 2014. Landslide susceptibility zonation based on the Analytic Hierarchy Process and information method. Applied Mechanics and Materials, 580-583, 2658-2662.

Reis, S., Yalcin, A., Atasoy, M., Nisanci, R., Bayrak, T., Erduran, M., Sancar, C., Ekercin, S., 2012. Remote sensing and GIS-based landslide susceptibility mapping using frequency ratio and analytical hierarchy methods in Rize province (NE Turkey). Environmental Earth Sciences, 66, 2063-2073.

Rozos, D., Bathrellos, G. D., Skillodimou, H. D., 2011. Comparison of the implementation of rock engineering system and analytic hierarchy process methods, upon landslide susceptibility mapping, using GIS: a case study from the Eastern Achaia County of Peloponnesus, Greece. Environmental Earth Sciences, 63, 49-63.

Saadatkhah, N., Kassim, A., Lee, M. L., 2014a. Qualitative and quantitative landslide susceptibility assessments in Hulu Kelang area, Malaysia. The Electronic Journal of Geotechnical Engineering, Bundle C, 19, 545-563.
Saadatkhah, N., Kassim, A., Lee, M. L., 2014 b. Susceptibility assessment of shallow landslides in Hulu Kelang Area, Kuala Lumpur, Malaysia using Analytical Hierarchy Process and Frequency Ratio. Geotechnical and Geological Engineering, 33 (1), 43-57.

Shafri, H. Z. M., Zahidi, I. M. S., Bakar, A. S., 2010. Development of landslide susceptibility map utilizing remote sensing and Geographic Information Systems (GIS). Disaster Prevention and Management, 19 (1), 59 - 69.

Sinop ÇED, 2007. İl Çevre ve Orman Müdürlüğü, Sinop İli Çevre Durum Raporu, 86 s., Sinop.

Solle, M. S., Mustafa, M., Baja, S., Imran, A. M., 2013. Landslide susceptibility zonation model On Jeneberang Watershed using Geographical Information System and Analytical Hierarchy Process. International Journal of Engineering and Innovative Technology, 2 (7), 174-179.

Solle, M. S., 2013. Landslide Susceptibility zonation model on Jeneberang Watershed Based On Geographical Information System and Analytical Hierarchy Process. The 2nd Southeast Asian Gateway Evolution Meeting (SAGE), Berlin, Germany.

Suh, J., Choi, Y., Roh, T. D., Lee, H. J., Park, H. D., 2011. National-scale assessment of landslide susceptibility to rank the vulnerability to failure of rock-cut slopes along expressways in Korea. Environmental Earth Sciences, 63, 619-632.

Tazik, E., Jahantab, Z., Bakhtiari, M., Rezaei, A., Alavipanah, S. K., 2014. Landslide susceptibility mapping by combining the three methods Fuzzy Logic, Frequency Ratio and Analytical Hierarchy Process in Dozain basin. The International Archives of the Photogrammetry, Remote Sensing and Spatial Information Sciences, Volume XL-2/W3, The 1st ISPRS International Conference on Geospatial Information Research, Tehran, Iran. 
Teimouri, M., Graee, P., 2012. Evaluation of AHP and Frequency Ratio Methods in landslide hazard zoning (Case Study: Bojnord Urban Watershed, Iran). International Research Journal of Applied and Basic Sciences, 3 (9), 1978-1984.

Thanh, L. N., DeSmedt, F., 2012. Application of an analytical hierarchical process approach for landslide susceptibility mapping in A Luoi district, Thua Thien Hue Province, Vietnam. Environmental Earth Sciences, 66, 1739-1752.

Vahidnia, M. H., Alesheikh, A., Alimohammadi, A., Hosseinali, F., 2009. Landslide hazard zonation using quantitative methods in GIS. International Journal of Civil Engineering, 7 (3), 176-189.

Wu, C. H., Chen, S. C., 2009. Determining landslide susceptibility in Central Taiwan from rainfall and six site factors using the analytical hierarchy process method. Geomorphology, 112, 190-204.

Yalçın A., 2005. Ardeşen (Rize) Yöresinin Heyelan Duyarlılığı Açısından İncelenmesi, Doktora, Fen Bilimleri Enstitüsü, Karadeniz Teknik Üniversitesi, Trabzon.

Yalcin, A., Bulut, F., 2007. Landslide susceptibility mapping using GIS and digital photogrammetric techniques: a case study from Ardesen (NETurkey). Natural Hazards, 41, 201-226.

Yalcin, A., 2008. GIS-based landslide susceptibility mapping using analytical hierarchy process and bivariate statistics in Ardesen (Turkey): Comparisons of results and confirmations. Catena, 72, 1-12.

Yalcin, A., Reis, S., Aydinoglu, A. C., Yomralioglu, T., 2011. A GIS-based comparative study of frequency ratio, analytical hierarchy process, bivariate statistics and logistics regression methods for landslide susceptibility mapping in Trabzon, NE Turkey. Catena, 85, 274-287.

Yamani, M., Hasanpoor, S., Mostafaei, A., Shadman Roodposhti, M., 2013. Mapping landslide hazard zonation in Great Karoon Aquifer Basin by Analytical Hierarchy Process (AHP) model in Geographic Information System (GIS) environment. Geography and Environmental Planning Journal, 48 (4), 13-16.

Yang, Z. H., Lan, H. X., Gao, X., Li, L. P., Meng, Y. S., Wu, Y. M., 2015. Urgent landslide susceptibility assessment in the 2013 Lushan earthquakeimpacted area, Sichuan Province, China. Natural Hazards, 75, 2467-2487.

Yanrong, L., Aydın, A., Xiqiong, X., Nengpan, J., Jianjun, Z., Özbek, A., 2012. Landslide susceptibility mapping and evaluation along a river valley in China. ACTA Geologica Sinica, 86 (4), 1022-1030.

Youssef, A. M., 2015. Landslide susceptibility delineation in the Ar-Rayth area, Jizan, Kingdom of Saudi Arabia, using analytical hierarchy process, frequency ratio, and logistic regression models. Environmental Earth Sciences, 73 (12), 8499-8518.

Youssef, A. M., Pradhan, B., Tarabees, E., 2011. Integrated evaluation of urban development suitability based on remote sensing and GIS techniques: contribution from the analytic hierarchy process. Arabian Journal of Geosciences, 4, 463-473.

Yoshimatsu, H., Abe, S., 2006. A review of landslide hazards in Japan and assessment of their susceptibility using an analytical hierarchic process (AHP) method. Landslides, 3, 149-158.

Zare, M., Jouri, M. H., Salarian, T., Askarizadeh, D., Miarrostami, S., 2014. Comparing of bivariate statistic, AHP and combination methods to predict the landslide hazard in northern aspect of Alborz Mt. (Iran). International Journal of Agriculture and Crop Sciences, 7 (9), 543-554. 